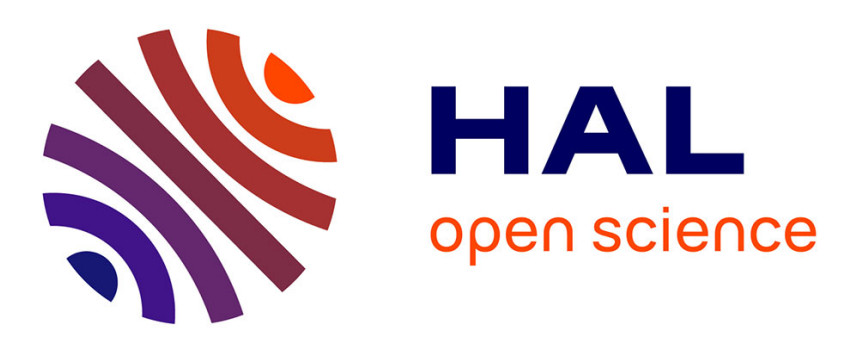

\title{
Physical characteristics of subduction interface type seismogenic zones revisited
}

\author{
Arnauld Heuret, Serge Lallemand, Francesca Funiciello, Claudia Piromallo, \\ Claudio Faccenna
}

\section{- To cite this version:}

Arnauld Heuret, Serge Lallemand, Francesca Funiciello, Claudia Piromallo, Claudio Faccenna. Physical characteristics of subduction interface type seismogenic zones revisited. Geochemistry, Geophysics, Geosystems, 2011, 12, pp.Q01004. 10.1029/2010GC003230 . hal-00617681

\section{HAL Id: hal-00617681 \\ https://hal.science/hal-00617681}

Submitted on 25 Jan 2016

HAL is a multi-disciplinary open access archive for the deposit and dissemination of scientific research documents, whether they are published or not. The documents may come from teaching and research institutions in France or abroad, or from public or private research centers.
L'archive ouverte pluridisciplinaire HAL, est destinée au dépôt et à la diffusion de documents scientifiques de niveau recherche, publiés ou non, émanant des établissements d'enseignement et de recherche français ou étrangers, des laboratoires publics ou privés. 

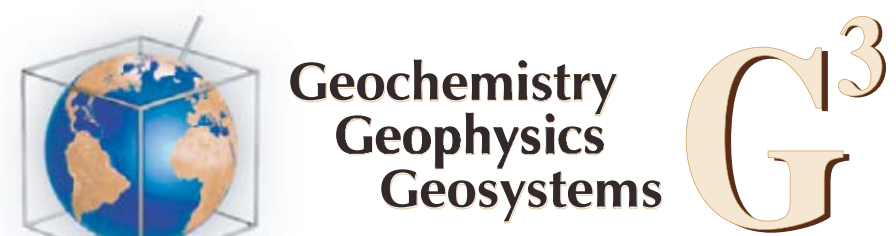

\title{
Physical characteristics of subduction interface type seismogenic zones revisited
}

\author{
Arnauld Heuret \\ Dipartimento di Scienze Geologiche, Università degli Studi "Roma Tre," I-00146 Rome, Italy \\ (heuret_arnauld@yahoo.fr)
}

Serge Lallemand

Géosciences Montpellier, Université Montpellier II, CC 60, F-34095 Montpellier, France

Francesca Funiciello

Dipartimento di Scienze Geologiche, Università degli Studi "Roma Tre," I-00146 Rome, Italy

Claudia Piromallo

INGV, I-00143 Rome, Italy

\section{Claudio Faccenna}

Dipartimento di Scienze Geologiche, Università degli Studi "Roma Tre," I-00146 Rome, Italy

[1] Based on global earthquake catalogs, the hypocenters, nodal planes, and seismic moments of worldwide subduction plate interface earthquakes were extracted for the period between 1900 and 2007. Assuming that the seismogenic zone coincides with the distribution of $5.5 \leq M<7$ earthquakes, the subduction interface seismogenic zones were mapped for $80 \%$ of the trench systems and characterized with geometrical and mechanical parameters. Using this database, correlations were isolated between significant parameters to identify cause-effect relationships. Empirical laws obtained in previous studies were revisited in light of this more complete, accurate, and uniform description of the subduction interface seismogenic zone. The seismogenic zone was usually found to end in a fore-arc mantle, rather than at a Moho depth. The subduction velocity was the first-order controlling parameter for variations in the physical characteristics of plate interfaces, determining both the geometry and mechanical behavior. As such, the fast subduction zones and cold slabs were associated with large and steep plate interfaces, which, in turn, had large seismic rates. The subduction velocity could not account for the potential earthquake magnitude diversity that was observed along the trenches. Events with $M_{w} \geq 8.5$ preferentially occurred in the vicinity of slab edges, where the upper plate was continental and the back-arc strain was neutral. This observation was interpreted in terms of compressive normal stresses along the plate interface. Large lateral ruptures should be promoted in neutral subduction zones due to moderate compressive stresses along the plate interface that allow the rupture to propagate laterally.

Components: 16,300 words, 15 figures, 1 table.

Keywords: subduction zones; seismicity; statistics.

Index Terms: 7240 Seismology: Subduction zones (1207, 1219, 1240); 8170 Tectonophysics: Subduction zone processes $(1031,3060,3613,8413)$.

Received 17 May 2010; Revised 27 October 2010; Accepted 10 November 2010; Published 19 January 2011.

Heuret, A., S. Lallemand, F. Funiciello, C. Piromallo, and C. Faccenna (2011), Physical characteristics of subduction interface type seismogenic zones revisited, Geochem. Geophys. Geosyst., 12, Q01004, doi:10.1029/2010GC003230. 


\section{Introduction}

[2] A significant portion of global seismicity occurs at convergent margins either within each deforming plate or along the plate interface [Byrne et al., 1988]. In particular, most $M_{w} \geq 8.0$ earthquakes are shallow depth events that originate along the frictional interfaces between subducting and overriding plates [e.g., Scholz, 2002]. The subduction plate interface seismicity thus accounts for approximately $90 \%$ of the total seismic moment that has been globally released during the last century [Pacheco and Sykes, 1992]. This finding highlights the primary role played by the long-term dynamics of convergent margins in short-term seismogenic processes.

[3] The contribution of each subduction toward the total released worldwide seismic moment is uneven, and large events are restricted to a subset of convergent margins. Despite the short length of instrumental time record data on earthquakes [McCaffrey, 2008], several authors have described the variability of subduction plate interfaces, both in terms of mechanical behavior and geometry [e.g., Ruff and Kanamori, 1980; Peterson and Seno, 1984; Kanamori, 1986; Jarrard, 1986; Tichelaar and Ruff, 1993; Pacheco et al., 1993; Oleskevich et al., 1999; Conrad et al., 2004], and have attempted to correlate these results with related tectonic parameters. In particular, possible relationships between the characteristics of subduction interface seismogenic zones and the subduction/ convergence velocity, slab age and upper plate absolute motion have been widely explored, providing insight into how the subduction plate interface behavior mirrors the complexities that occur at convergent margins.

[4] Ruff and Kanamori [1980] and Jarrard [1986] were the first to note that the earthquake magnitude potential of subduction zones is positively correlated with relative plate motions. Faster subduction zones enhance the triggering of the largest events and vice versa. McCaffrey [1994, 1997b] explained that such a correlation is predictable using the Gutenberg and Richter [1954] recurrence relation. However, these data do not explain why the fastest subduction zones (e.g., Tonga or the New Hebrides) are not associated with large earthquakes. Furthermore, these results do not elucidate why the seismic coupling coefficients calculated by Pacheco et al. [1993] are not correlated with subduction velocities.

[5] The negative correlation observed by Ruff and Kanamori [1980] between the earthquake mag- nitude potential of subduction zones and the slab age is frequently debated. The original model links the subducting plate age and convergence velocity to the sinking and trench retreat rates of a plate, respectively, which affect the pressures exerted along the plate interface [Ruff and Kanamori, 1980]. However, new data based on historical/paleoseismic records and the occurrence of the great Sumatra earthquake, no longer support the age- $M_{w}$ correlation [Pacheco et al., 1993; McCaffrey, 1997b; Stein and Okal, 2007; Gutscher and Westbrook, 2009].

[6] The overriding plate absolute motion has been indicated as another potential controlling factor of the seismic coupling that occurs through pressure exerted along a plate interface [Uyeda and Kanamori, 1979; Peterson and Seno, 1984; Scholz and Campos, 1995; Conrad et al., 2004]. However, Pacheco et al. [1993] reached an opposing conclusion.

[7] Contradictory results also appear when investigating the role played by seismogenic zone geometry on seismic activity. Kelleher et al. [1974] found that the size of events increases with the width of the contact zone; however, Pacheco et al. [1993] found no significant correlation when considering the seismic coupling coefficient, largest event magnitude, or cumulated seismic moment magnitude.

[8] Moreover, as most of the seismogenic zones are confined to depth transitions corresponding to temperatures in the ranges of $100^{\circ} \mathrm{C}-150^{\circ} \mathrm{C}$ and $350^{\circ} \mathrm{C}-450^{\circ} \mathrm{C}$ [Tichelaar and Ruff, 1993; Hyndman and Wang, 1993; Wang et al., 1995; Hyndman et al., 1995, 1997; Oleskevich et al., 1999; Currie et al., 2002], the updip and downdip limits and the seismogenic zone geometry are often interpreted as being thermally controlled. The former limit is related to the diagenesis and low-grade metamorphism, producing minerals of higher bulk rigidity within the subducting sediments [e.g., Vrolijk, 1990; Moore and Saffer, 2001]. The latter limit marks the beginning of the aseismic sliding regime and has been related to the brittle-ductile transition of crustal materials at the Moho intersection, below which the water released by the slab serpentinizes the mantle fore arc, enhancing the formation of stable sliding minerals [e.g., Hyndman et al., 1997; Peacock and Hyndman, 1999; Oleskevich et al., 1999; Hyndman and Peacock, 2003]. Again, Pacheco et al. [1993] found no relationship between the downdip width of the seismogenic zone and the slab 
age, convergence velocity or absolute motion of the overriding plates.

[9] Ruff and Tichelaar [1996] observed a correlation between the coastline location and downdip limit of the major circum-Pacific subduction interface seismogenic zones. These authors inferred that both of these characteristics are determined by the intersection of the overlying plate's Moho with the slab top and downdip edge of the seismogenic zone. However, the seismogenic zones of several subduction zones (e.g., Japan and Sumatra) have recently been found to extend into the fore-arc mantle [Seno, 2005; Dessa et al., 2009].

[10] In this study, the diversity of the subduction interface seismogenic zones was analyzed using data from global seismicity catalogs that covered a time period of 107 years. Parameters describing the plate interface seismogenic zone geometry (e.g., dip, maximal and minimal depths and maximal and minimal distances to trench) and mechanical behavior (e.g., seismic rate, moment release rate, largest magnitude and seismic coupling coefficient) were calculated and added to the SubductionZones database [Heuret, 2005] to enable statistical comparisons with a wide range of updated tectonic parameters related to worldwide convergent margins. The continuous development of global earthquake catalogs, such as the CMT Harvard catalog [Dziewonski and Woodhouse, 1981], EHB hypocenter catalog [Engdahl et al., 1998] and Centennial catalog [Engdahl and Villaseñor, 2002], as well as 15 additional years of earthquake records, are expected to improve the completeness, accuracy and uniformity of this data set.

\section{Data}

[11] In the present section, we describe the parameters used to characterize the subduction interface seismogenic zone (see the notation section) and the adopted methodology used for their sampling and determination.

\subsection{Sampling the Subduction Seismogenic Zone}

[12] The location of the seismogenic zone can be defined using different approaches: (1) the area of the coseismic slip, as estimated for a selected $M_{w} \geq$ 8.5 earthquake (this can be estimated from seismic and tsunami waveform data, as well as from geodetic data sets [e.g., Satake, 1993]; this parameter is often assumed to be approximately equivalent to the area of the aftershock distribution [e.g., Schwartz and DeShon, 2007]); (2) the area locked during the interseismic period, as inferred from geodetic measurements of strain accumulation induced at the surface by plate interface locking [e.g., Savage, 1983; Thatcher and Rundle, 1984; Dixon, 1993; Lundgren et al., 1999; Norabuena et al., 1998, 2004] (it is commonly assumed that the fault area that is fully locked during the interseismic period is the same area that will subsequently rupture in the next extreme event); and (3) the area defined by the distribution of all of the $M_{w}$ 5.5-7.0 thrust earthquake nucleation locations (i.e., not that of a single event) [Pacheco et al., 1993].

[13] In the present study, following Pacheco et al. [1993], we assumed that the seismogenic zone of subduction boundaries coincides with the distribution of shallow (depth $\leq 70 \mathrm{~km}$ ) and moderately sized $\left(5.5 \leq M_{w}<7.0\right)$ subduction thrust fault earthquakes. The seismogenic zone was mapped by assessing its location, dip, depth, downdip limit and updip limit to determine the parameters that control seismic activity along the plate interface.

\subsubsection{Methodology}

[14] Three complementary global earthquake catalogs were utilized to describe the location, geometry and seismic activity of the subduction interface seismogenic zone: the Harvard CMT catalog, the EHB catalog and the Centennial catalog (see auxiliary material). ${ }^{1}$ The $1976-2007$ Harvard CMT catalog was used to identify the $M_{w} \geq 5.5$ subduction plate interface thrust earthquakes. The mapping of the seismogenic zone was improved by using, for each of the identified thrust events, the location given in the EHB catalog. The Centennial catalog was used to extend this study to the 1900 1975 time period for $M_{w} \geq 7.0$ earthquakes.

[15] For each subduction zone, a set of $2^{\circ}$ wide trench-normal transects were constructed that were spaced by $1^{\circ}$ along the trench. For each of the 505 resulting transects, the subduction interface seismogenic zone was mapped by selecting from the Harvard CMT catalog the shallow (depth $\leq 70 \mathrm{~km}$ ) thrust earthquakes for which one nodal plane was consistent with the plate interface geometry and orientation (see auxiliary material). The events selected from the Centennial catalog included all of the shallow and $M_{w} \geq 7.0$ events during the 1900-

\footnotetext{
${ }^{1}$ Auxiliary materials are available in the HTML. doi:10.1029/
} 2010GC003230. 


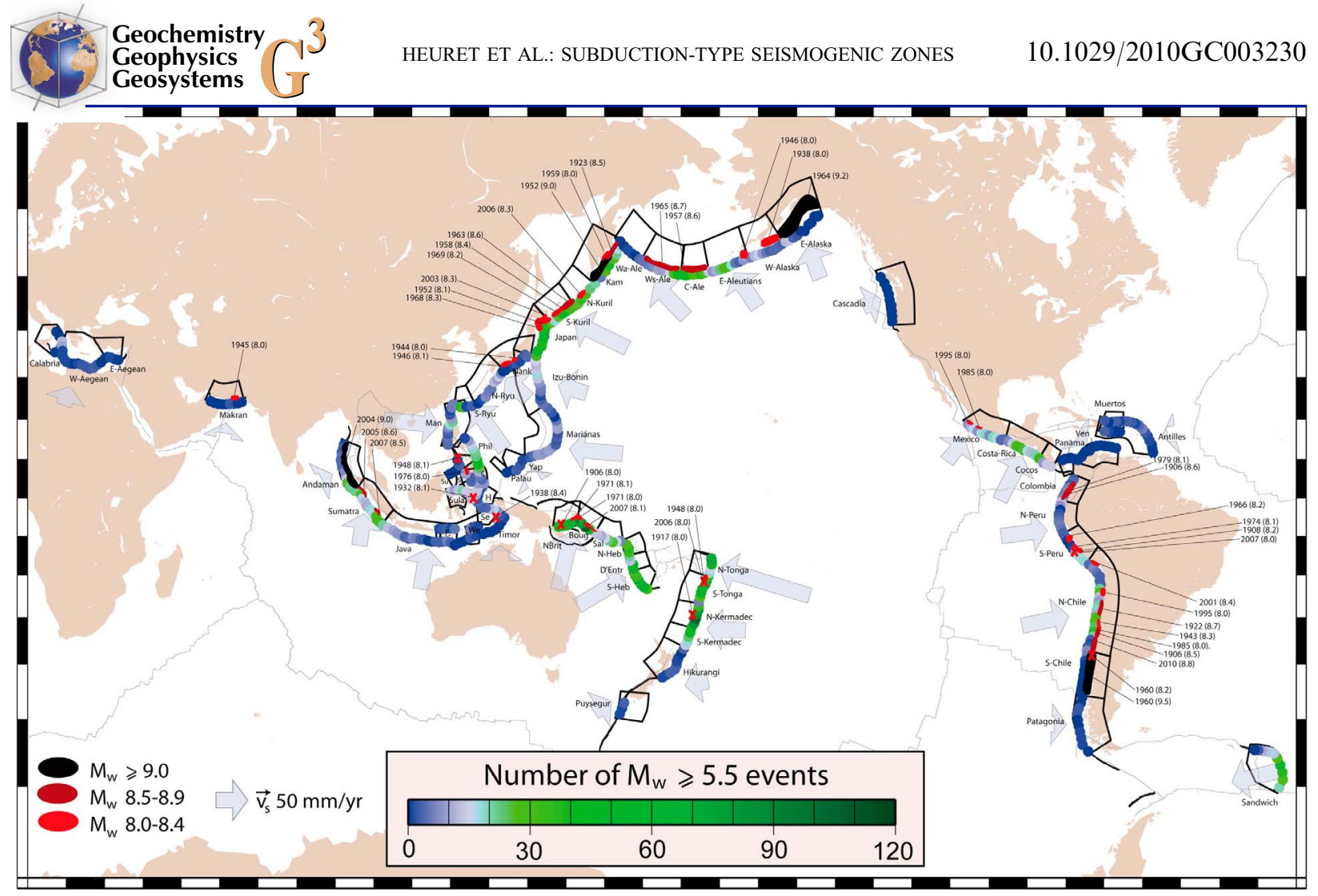

Figure 1. Map of the subduction interface seismicity and trench segmentations. The trench segments are delimited by black lines. The rupture area of the $M_{w} \geq 8.0$ subduction interface events (1900-2007) is represented by red and black ellipses. The rupture areas were taken from McCann et al. [1979], Kanamori [1986], Schwartz et al. [1989], Byrne et al. [1992], Tichelaar and Ruff [1993], Johnson et al. [1994], Ishii et al. [2005], Fedotov et al. [2007], Ruppert et al. [2007], Bilek [2009], and Madariaga et al. [2010]. Red crosses are used here to indicate $M_{w} \geq 8.0$ events that did not have available rupture area data. Colored dots represent, by each $1^{\circ}$ of trench, the number of $M_{w} \geq$ 5.5 subduction interface events (1976-2007). Subduction velocities [Heuret, 2005] are represented by blue arrows. Trench segment symbols are defined as in Table 1.

1975 time period that were located on the slab between the volcanic arc and $50 \mathrm{~km}$ in front of the trench. All of these events were supposed to occur along the plate interface.

[16] The 505 transects were merged into 62 segments so that the rupture areas inferred for $M_{w} \geq$ 8.0 earthquakes were included in single segments (Figure 1; see auxiliary material).

\subsubsection{Parameters of the Subduction Interface Seismogenic Zone}

\subsubsection{Geometrical Parameters}

[17] Distributions of the earthquake dip, distance to trench and depth for $5.5 \leq M_{w}<7.0$ events were used as mapping tools for delimitation of the seismogenic zone, with the assumption that all of the identified thrust earthquakes occurred on plate interfaces and not on secondary faults (Figure 2; see auxiliary material). The cutoff for the moment magnitude $M_{w} \geq 5.5$, as shown by Pacheco et al. [1993], enabled a reliable determination of the earthquake source and depth from the Harvard CMT data. When less than ten events with $M_{w}$ 5.57.0 were recorded, the seismicity was considered as too sparse to allow any reasonable mapping from the global seismicity catalogs alone. Finally, 42 of the initial set of 62 segments were mapped using the global catalogs, and Cascadia, E-Alaska, southern Chile and Nankai were constrained using results presented by Oleskevich et al. [1999]. The geometries of the 16 remaining $N_{5.5-7.0}<10$ event segments were not measured. Examples of the trench-normal hypocenter distributions are presented in Figure 2 (the entire set is in the auxiliary material).

[18] Several previous studies focused on the determination of seismogenic zone depth limits [e.g., Pacheco et al., 1993; Tichelaar and Ruff, 1993], 




(b)
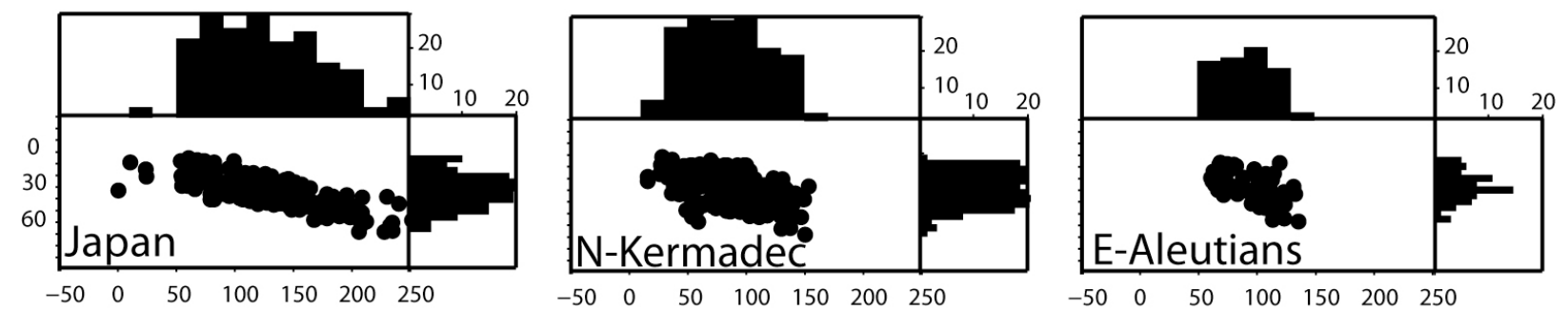

Figure 2. (a) The parameters defining the subduction plate interface seismogenic zone geometry derived from $M_{w}$ 5.5-7.0 event distributions. $U$ and $D$ define the updip and the downdip limits of the seismogenic zone, respectively. Their respective coordinates are $\left[U_{x} ; U_{z}\right]$ and $\left[D_{x} ; D_{z}\right]$, as defined by the 5 th and 95 th percentiles of the depth and distance-to-trench distributions. $W$ and $\theta$ define the downdip width and the dip of the seismogenic zone. $W_{x}$ and $W_{z}$ define the horizontal and vertical extents of the seismogenic zone. (b) Examples of hypocenter distributions of the subduction plate interface seismicity. Black dots represent $M_{w}$ 5.5-7.0 subduction interface events.

whereas other reports have focused on the characterization of distance-to-trench limits [e.g., Ruff and Tichelaar, 1996]. Here, both of these limits were analyzed together for the first time. The horizontal $(x)$ and vertical $(z)$ coordinates of the seismogenic zone updip $(U)$ and downdip $(D)$ limits were calculated. In a similar manner to Pacheco et al. [1993], the vertical limits $\left(U_{z}\right.$ and $D_{z}$ ) were taken to correspond to the 5th and 95th percentiles, respectively, of the thrust event depth distribution. In the same way, the trenchward and arcward horizontal limits of the seismogenic zone $\left(U_{x}\right.$ and $\left.D_{x}\right)$ were defined as the 5th and 95th percentiles, respectively, of the trench-earthquake distance distribution (Figure 2). This percentile choice enabled a reduction in uncertainties of the depth and distance-to-trench determinations due to outliers in the distribution caused by unknown errors.
[19] We assumed $\left[U_{x} ; U_{z}\right]$ and $\left[D_{x} ; D_{z}\right]$ as the coordinates of the updip $(U)$ and downdip $(D)$ limits, respectively, of the seismogenic zone. Thus, the seismogenic zone downdip width $W$ is given by the distance between $U$ and $D$, and the dip angle $\theta$ is determined by the angle between the horizontal and the line (UD) (Figure 2). The horizontal and vertical extents of the seismogenic zone $\left(W_{x}\right.$ and $\left.W_{z}\right)$ were also constrained with this method.

\subsubsection{Mechanical Parameters}

[20] A given trench segment is characterized by its along-strike length $L$, its downdip width $W$ and by $N$ plate interface thrust events that have been recorded during a period $T$. Based on these events, the mechanical behavior of the segment can be described using quantitative measures of the seismicity, i.e., the seismic rate, released seismic 
energy, and seismic coupling coefficient (see auxiliary material). For the $M_{w}$ calculation, the momentmagnitude relation by Kanamori [1977] was utilized:

$$
M=\left(\log M_{0}-16.1\right) / 1.5 .
$$

[21] The seismic rate $\tau$ was defined as the number of subduction interface events recorded during a century and along $1000 \mathrm{~km}$ of a trench. This parameter was computed across the selection of $M_{w} \geq 5.5$ plate interface events from the Harvard CMT catalog.

[22] The amount of seismic energy released and the seismic coupling parameters were computed for the entire period of 107 years covered by the 19001975 Centennial catalog and the 1976-2007 Harvard catalog. The seismic energy released along the trench segment is described by $M_{\max }$, the maximum earthquake magnitude observed along the segment, and the moment release rate $M R R$. MRR is defined as the cumulated seismic moment released by $N$ events of the segment during a century and along $1000 \mathrm{~km}$ of the trench [Peterson and Seno, 1984]:

$$
M R R=\left(\Sigma M_{o}^{i} / T L\right) 10^{5}
$$

where $M_{o}^{i}$ is the seismic moment released by an individual earthquake. Subsequently, $M R R$ was converted into an equivalent representative magnitude $M_{M R R}$ using equation (1).

[23] The seismic coupling coefficient $\chi$ [Peterson and Seno, 1984; Pacheco et al., 1993; Scholz and Campos, 1995; McCaffrey, 1997a; Scholz, 2002] is determined by the ratio between the seismic slip rate $v_{s s}$ and the subduction velocity $v_{s}$, as computed from global plate models. The seismic coupling coefficient was estimated by taking into account either the total subduction rate $v_{s}$ or its trenchnormal component $v_{s(n)}$, yielding the corresponding coefficients of $\chi$ and $\chi_{(n)}$, respectively. The seismic slip rates were computed according to the relationship given by Brune [1968] for a given subduction zone:

$$
v_{s s}=\Sigma M_{o}^{i} /(\mu T W L)
$$

where the plate interface rigidity $\mu$ is taken as an average $\left(5 \times 10^{10} \mathrm{~N} / \mathrm{m}^{2}\right)$.

\subsection{Other Subduction Parameters}

[24] Most of the other subduction parameters (e.g., subducting plate age, absolute and relative plate motions, upper plate strain, slab geometry, arctrench distance and upper plate nature) were extracted from the global database already presented by Heuret [2005], Heuret and Lallemand [2005], and Lallemand et al. [2005]. For the present study, the number of transects was doubled with respect to earlier studies (one transect per trench degree, approximately $100 \mathrm{~km}$, along the subduction zones), and the data were averaged for each of the 62 segments.

[25] The relative plate motions are described in the NUVEL1A model [DeMets et al., 1990], and the absolute plate motions were estimated using the HS3 hot spot reference frame [Gripp and Gordon, 2002]. The values of $v_{s}, v_{c}, V_{u p}, V_{t}$ and $V_{s u b}$ were defined as the velocities of the subduction, convergence, upper, trench and subducting plates, respectively (with lowercase letters used for relative velocities and uppercase letters for absolute velocities). The value of $V_{t}$ was calculated by subtracting the back-arc deformation velocity $v_{d}$ (estimated using geodetic measurements) from $V_{u p}$ while neglecting erosion and accretion at the toe of the margin's wedge. The subduction velocity $v_{s}$ is the relative motion of the subducting plate with respect to the trench $\left(v_{s}=V_{\text {sub }}-V_{t}\right)$, and $v_{c}$ is the relative motion of the subducting plate with respect to the upper plate $\left(v_{c}=V_{s u b}-V_{u p} ; v_{s}=v_{c}\right.$ if $\left.v_{d}=0\right)$.

[26] The type of upper plate strain (UPS) was determined from the focal mechanisms of shallow earthquakes occurring at depths less than $40 \mathrm{~km}$ from the surface of the upper plate, far from the subduction interface. The simplified strain classification system of three classes, as described by Lallemand et al. [2008], was utilized: extensional (rifting or spreading), neutral (no significant deformation or strike-slip), and compressive (shortening). Upper plate nature $(U P N)$ differentiate between oceanic and continental fore arcs.

[27] The slab age $A$ was extracted from the Müller et al. [1997] digital age grid. The thermal parameter $\varphi$ was calculated from the initial temperature of the subducting plate (proportional to $A$ ) and its warming velocity at depth [Kirby et al., 1996].

$$
\varphi=A v_{s} \sin \theta
$$

[28] The mean arc-trench distance $d_{\text {arc-t }}$ was calculated normal to the trench. The location of the active volcanoes was taken from the Smithsonian Institution Database [Siebert and Simkin, 2002]. 
Table 1. Seismogenic Zone Parameters of the Worldwide Subduction Zones ${ }^{\text {a }}$

\begin{tabular}{|c|c|c|c|c|c|c|c|c|c|c|c|c|c|c|c|c|c|}
\hline \multirow[b]{2}{*}{ Subduction } & \multirow[b]{2}{*}{$L$} & \multicolumn{12}{|c|}{ 1976-2007 } & \multicolumn{4}{|c|}{ 1900-2007 } \\
\hline & & $N$ & $N_{7}$ & $N_{5.5-7}$ & $\tau$ & $U_{z}$ & $D_{z}$ & $W_{z}$ & $U_{x}$ & $D_{x}$ & $W_{x}$ & $W$ & $\theta$ & $M_{\max }$ & $M_{M M R}$ & $\chi$ & $\chi(n)$ \\
\hline alabria $(\mathrm{Cal})$ & 784 & 0 & 0 & 0 & 0 & & & & & & & & & 7.0 & 7.3 & & \\
\hline -Aegean & 74 & 17 & 0 & 17 & 31 & 6 & 45 & 39 & 124 & 298 & 174 & 179 & 12 & 7.8 & 7.8 & 0.02 & 0.02 \\
\hline E-Aegean (E-Aeg) & 55 & 1 & 0 & 1 & 7 & & & & & & & & & 5.9 & 6.4 & & \\
\hline Makran (Mak) & 037 & 2 & 0 & 2 & 6 & & & & & & & & & 8.0 & 8.0 & & \\
\hline Andaman (And) & 693 & 67 & 4 & 63 & 128 & 11 & 50 & 39 & 6 & 245 & 239 & 243 & 9 & 9.0 & 8.8 & 0.98 & 1.12 \\
\hline Sumatra (Sum) & - & 121 & 7 & & 294 & 20 & 53 & 33 & 36 & 7 & 171 & 174 & 11 & & & .32 & 0.43 \\
\hline Java & $1 / 3$ & 39 & 2 & 37 & 71 & 15 & 57 & 42 & 44 & & 183 & 188 & 13 & 7.8 & & .02 & 0.02 \\
\hline Timor (Tim) & 524 & 17 & 0 & 17 & 22 & 8 & 31 & 23 & 64 & 171 & 107 & 110 & 12 & 8.4 & 8.2 & .21 & 0.23 \\
\hline Seram (Se) & 62 & 21 & 0 & 21 & 121 & 15 & 42 & 27 & 39 & 110 & 71 & 76 & 20 & 7.5 & 7.8 & .02 & 0.08 \\
\hline (e) & & 7 & 1 & 6 & 50 & 10 & 41 & 31 & 9 & 28 & 19 & 36 & 58 & 7.5 & 7.9 & .18 & 0.19 \\
\hline Flores (F) & 3 & 9 & 0 & 9 & 44 & 10 & 66 & 56 & 37 & 50 & 13 & 57 & 77 & 6.3 & 7.1 & 0.00 & 0.00 \\
\hline 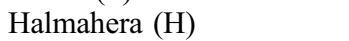 & 33 & 8 & 0 & 8 & 37 & 35 & 65 & 30 & -41 & 32 & 73 & 79 & 22 & 7.0 & 7.5 & 0.04 & 0.04 \\
\hline (C) & 8 & 49 & 0 & 49 & 165 & 10 & 59 & 49 & -31 & 61 & 92 & 104 & 28 & 8.1 & 8.4 & 0.12 & 0.13 \\
\hline Sulawesi (Su & 1 & 37 & 5 & 32 & 175 & 14 & 43 & 29 & 68 & 124 & 56 & 62 & 28 & 7.9 & 8.2 & 0.10 & 0.27 \\
\hline Sulu (Su) & & 3 & 1 & 2 & 13 & & & & & & & & & 8.1 & & & \\
\hline ( & & 14 & 2 & 12 & 86 & 10 & 51 & 41 & 2 & 35 & 33 & 52 & 1 & 80 & & 30 & 0.41 \\
\hline & & 27 & 0 & & 146 & 12 & 52 & 40 & 86 & & 90 & 98 & 24 & & & 0.02 & 0.03 \\
\hline Phil) & & & 8 & & & 15 & 55 & 40 & 23 & & 70 & & 0 & & & & 0.12 \\
\hline & & 42 & 1 & & & 12 & 50 & 38 & 38 & & 62 & 3 & 32 & & & .14 & 0.15 \\
\hline & & 35 & 0 & & 0 & 20 & 53 & 33 & 70 & & & & 16 & & & .04 & 0.04 \\
\hline & & 6 & 1 & J & 20 & 12 & 35 & 23 & 30 & 160 & 130 & 132 & 10 & 8.1 & J & 0.22 & 0.27 \\
\hline Palau (Pal) & & 0 & 0 & 0 & 0 & & & & & & & & & 0.0 & 6.1 & & \\
\hline Yap & & 4 & 0 & 4 & 19 & & & & & & & & & 7.7 & 7.8 & & \\
\hline 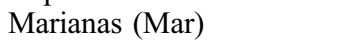 & 01 & 46 & 0 & 46 & 70 & 8 & 51 & 43 & 31 & 14 & 83 & 93 & 28 & 7.5 & 77 & .02 & 0.02 \\
\hline Izu & 367 & 54 & 0 & 5 & 127 & 10 & 45 & 35 & 15 & 113 & 98 & 104 & 20 & 7. & & 0.05 & 0.05 \\
\hline Japa & 4 & 215 & 10 & 205 & 671 & 10 & 60 & 50 & 57 & 210 & 153 & 161 & 18 & 8 & & 0.24 & 0.24 \\
\hline O & & 141 & 11 & 1 & 589 & 16 & 54 & 38 & 50 & 144 & 94 & 102 & 22 & & 9 & 0.68 & 0.75 \\
\hline $\mathrm{N}-\mathrm{K}$ & & 84 & 2 & 82 & 467 & 10 & 51 & 41 & 52 & & 85 & 95 & 26 & & & 0.26 & 0.26 \\
\hline & & & 2 & & & 11 & 61 & 50 & 60 & 158 & 98 & 110 & & & & 1.17 & 1.19 \\
\hline & & 5 & 1 & 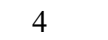 & 2 & & & & & & & & & & & & \\
\hline & & & 4 & & & 11 & 48 & 37 & & & v & & 1 & & & & 1.57 \\
\hline & & 5 & 3 & & & 14 & 56 & 42 & 82 & & 61 & & 5 & & & 79 & 0.97 \\
\hline & & 73 & 0 & 73 & 289 & 10 & 50 & 40 & 61 & 22 & 61 & 72 & 33 & & 2 & 12 & 0.13 \\
\hline V & & 31 & 1 & 3 & 137 & 18 & 55 & 37 & 70 & 153 & 83 & 91 & 24 & .0 & .2 & .10 & 0.10 \\
\hline $\mathrm{E}-A$ & 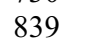 & 15 & 0 & 15 & 58 & 7 & 54 & 47 & 69 & 243 & 174 & 180 & 15 & 9.2 & 9.2 & 1.82 & 1.93 \\
\hline Cas & 52 & 0 & 0 & 0 & 0 & 5 & 30 & 25 & 5 & 130 & 125 & 127 & 11 & 6 & 7.6 & 0.01 & 0.01 \\
\hline & & 60 & 9 & 5 & 149 & 11 & 41 & 30 & 45 & 113 & 68 & 74 & 24 & & & 0.43 & 0.45 \\
\hline Cos & 11 & 119 & 3 & & & 15 & 63 & 48 & 48 & 139 & 91 & 103 & 28 & & & 0.05 & 0.05 \\
\hline & & 24 & 2 & & & 14 & 48 & 34 & 32 & & 133 & & & & & 0.03 & 0.03 \\
\hline & & & 4 & & & 11 & 50 & 39 & 1 & & 92 & & & & & 8 & 0.66 \\
\hline & & & 1 & & & 10 & 44 & 3 & & & & & & & & & 0.03 \\
\hline & & 3 & 3 & & & 10 & 4 & & & & 7 & & & & & & 0.32 \\
\hline & & 16 & 12 & 14 & 205 & 12 & 51 & 39 & 38 & 135 & 97 & 105 & 22 & & 8 & 59 & 0.65 \\
\hline & & 8 & 0 & o & 23 & 5 & 50 & 45 & 25 & 210 & 185 & 190 & 14 & & 9.5 & 2.50 & 2.64 \\
\hline $\mathrm{Pa}$ & & 3 & 0 & 3 & 8 & & & & & & & & & 7.8 & 7.8 & & \\
\hline & & 16 & 0 & 16 & 25 & 14 & 48 & 34 & 40 & 204 & 164 & 168 & 12 & 7.9 & 7.9 & 0.08 & 0.13 \\
\hline & & 3 & 0 & 3 & 15 & & & & & & & & & 5.7 & 6.9 & & \\
\hline & & 0 & 0 & 0 & 0 & & & & & & & & & & & & \\
\hline & & 0 & 0 & 0 & 0 & & & & & & & & & & & & \\
\hline & & 89 & 0 & 89 & 274 & 10 & 60 & 50 & 28 & 147 & 121 & 151 & 22 & 7. & 1.0 & 0.02 & 0.02 \\
\hline & & 4 & 3 & 1 & 28 & & & & & & & & & 7.4 & 8.0 & & \\
\hline & & 8 & 0 & 8 & 2 & 1 & 6 & 60 & & & & & & & 70 & 2 & 0.03 \\
\hline & & 66 & 0 & & & 6 & 64 & 5 & & & & & & & & & 0.01 \\
\hline & & & 9 & & & 10 & & 4 & 3 & & & & & & & & 0.21 \\
\hline S-Tor & - & 151 & 2 & 149 & & 4 & 45 & 41 & 30 & & 69 & 80 & J1 & & & 0.12 & 0.12 \\
\hline N-Ton & 732 & 129 & 1 & 128 & 568 & 8 & 42 & 34 & 24 & 116 & 92 & 98 & 21 & 8.0 & 8.3 & 0.04 & 0.04 \\
\hline S-New He & 791 & 143 & 7 & 136 & 583 & 10 & 53 & 43 & 29 & 100 & 71 & 83 & 31 & 7.9 & 8.4 & .11 & 0.11 \\
\hline D'Entrecasteaux (D'ent) & 471 & 80 & 3 & 77 & 548 & 14 & 42 & 28 & 20 & & 67 & 72 & 22 & 7.6 & 8.3 & 0.14 & 0.16 \\
\hline $\mathrm{N}-\mathrm{N}$ & 566 & 70 & 4 & 66 & 399 & 10 & 64 & 54 & 3 & & 84 & 100 & 33 & 7.7 & 8.4 & 0.08 & 0.08 \\
\hline Salo & 934 & 61 & 8 & 53 & 211 & 11 & 46 & 35 & 5 & 85 & 80 & 87 & 24 & 7.9 & 8.4 & 0.11 & 0.26 \\
\hline & & 152 & 4 & 148 & 780 & 10 & 63 & 53 & 24 & 105 & 81 & 97 & 3 & 8.1 & 8.6 & 0.19 & 0.20 \\
\hline New Britain (NBrit) & 804 & 202 & 6 & 196 & 810 & 17 & 63 & 46 & 27 & 139 & 112 & 121 & 22 & 8.1 & 8.7 & 0.20 & 0.24 \\
\hline
\end{tabular}




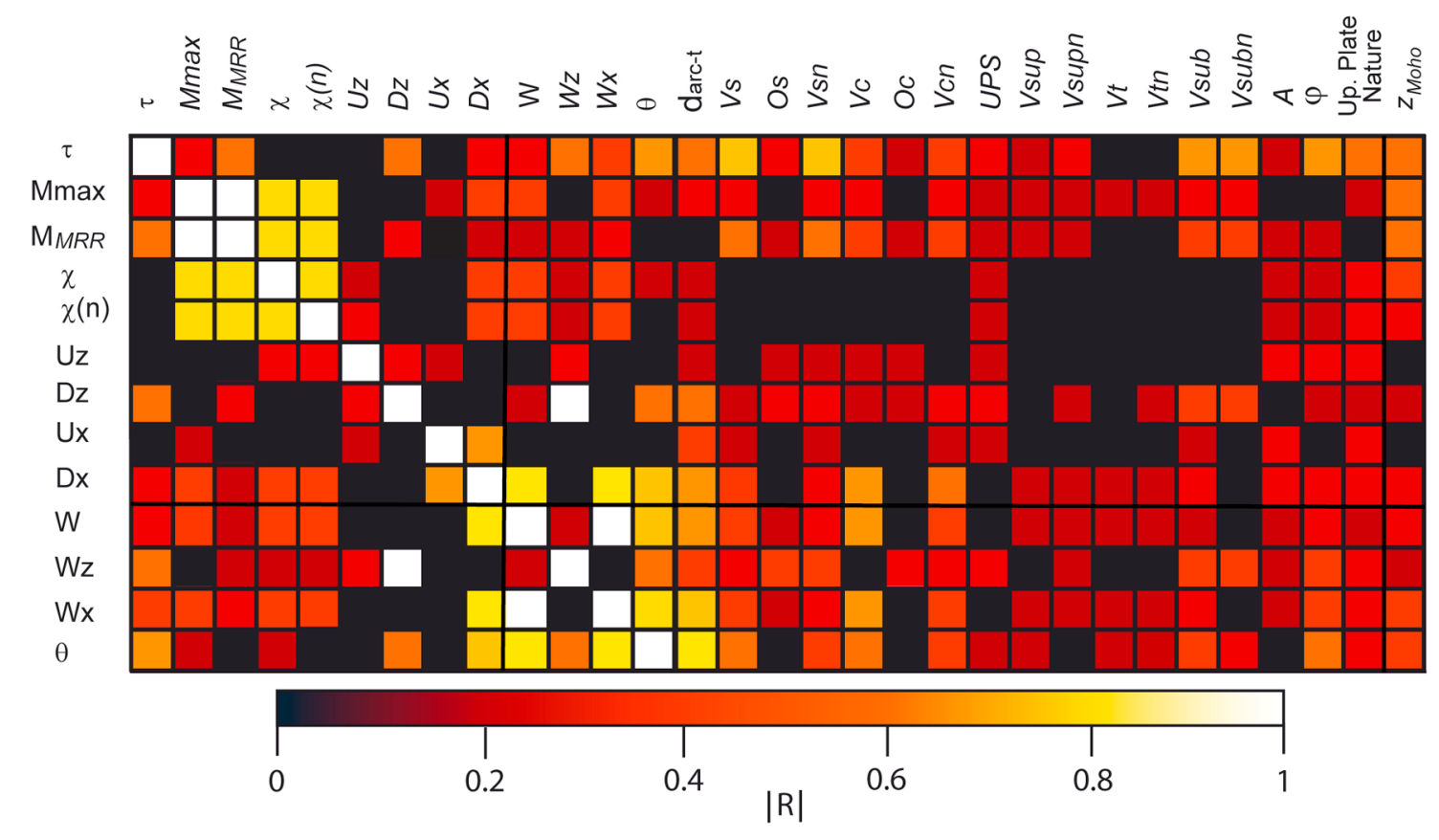

Figure 3. Pearson's product-moment correlation coefficient $\mathrm{R}$ of linear bivariate regressions between seismogenic zone parameters and other independent subduction parameters. Correlation coefficient signs (positive or negative) are given in Table S1 in the auxiliary material for each of the relations discussed in the study. Symbols are defined as in the notation section.

[29] Wada and Wang [2009] compiled estimates of the upper plate Moho depth below the fore arcs $z_{\text {Moho }}$ for 17 of the selected 62 trench segments. These values were used to calculate $\Delta z$, the depth difference between the fore-arc Moho and the downdip limit of the subduction interface seismogenic zone:

$$
\Delta z=z_{M o h o}-D_{z}
$$

\section{Statistical Analysis}

[30] There were two main objectives for the statistical analysis carried out on the subduction plate interfaces: (1) to describe the diversity of the subduction plate interface physical characteristics for the 62 worldwide subduction zones (Table 1) and (2) to determine quantitative relationships between the subduction plate interface parameters and independent subduction parameters that have already been compiled in previous publications [Heuret and Lallemand, 2005; Lallemand et al., 2005; Heuret,
2005; Wu et al., 2008; Wada and Wang, 2009], including the arc-trench distance, relative and absolute plate kinematics, upper plate strain, age and thermal parameter of the subducted plate, upper plate nature and fore-arc Moho depth.

[31] The diversity of the physical characteristics of the subduction interface was described using various statistical indicators (e.g., mean and median values, standard deviation and minimum and maximum values), histograms and maps of the alongtrench variations for each subduction interface parameter.

[32] The significance of the bivariate relationships between the subduction plate interface parameters and independent variables was statistically tested using linear regression analysis. The potential to fit the data using this type of linear regression analysis was initially quantified using the Pearson's productmoment correlation coefficient $\mathrm{R}$. The correlation coefficients are presented in Figure 3. This analysis shed light on the first-order parameters, identifying the most relevant relationships between the

\footnotetext{
Notes to Table 1:

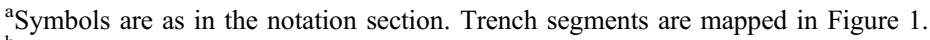

${ }^{\mathrm{b}}$ Geometry of the subduction interface seismogenic zone constrained using results presented by Oleskevich et al. [1999].

${ }^{\mathrm{c}}$ The 2010, $M_{w}=8.8$ Maule event [Madariaga et al., 2010] has been included in the present study.
} 
subduction interface characteristics and other subduction parameters. As the $\mathrm{R}$ values were quite low on average (mean $\mathrm{R}$ value was $0.25 \pm 0.21$ ), section 3 only describes the most statistically significant relationships, as well as the most meaningful ones, in terms of the physics and mechanisms of the system. To enable a more detailed test of the reliability of each described linear regression, we also considered the standard error $\left(\sigma_{e}\right)$ and the results of $t$ tests for the slope and intercept values at a 95\% confidence level. We have arbitrarily considered as significant the relations that had $|\mathrm{R}|>0.30$ and $p$ values $\leq 0.05(5 \%)$. The corresponding trends were then represented in Figures 7, 9, and 12. Figures 7, 9, and 12 account for the standard errors of the $y$ intercept and slope (see auxiliary material for the detailed analysis).

[33] Outliers were frequent in most of the bivariate relationships that have been analyzed. Some of this outliers were constant from one relation to the other. This was particularly verified for the relationships between $v_{s}$ (and $\varphi$ ) and most of the subduction interface parameters (Figures 7 and 9). Most of these relationships have appeared nonlinear for the fastest subductions, i.e., for northern Tonga and northern New Hebrides. Nonlinearity and alternative relationships (e.g., exponential or seconddegree polynomial) were difficult to test statistically because only a few fast subductions exist $(80 \%$ of $v_{s}$ values were lower than $80 \mathrm{~mm} \mathrm{yr}^{-1}$ and only northern Tonga and northern New Hebrides $v_{s}$ values were larger than $130 \mathrm{~mm} \mathrm{yr}^{-1}$ ). Thus, for Figures 7 and 9, we have decided to test the reliability of linear relationships both considering or excluding northern Tonga and northern New Hebrides (see auxiliary material). These two segments are however neglected in the correlations presented in Figures 7 and 9.

\subsection{Geometry of the Subduction Interface Seismogenic Zone}

\subsubsection{Global Variability}

[34] Most of the seismogenic zones exhibited shallow dipping geometries (Figure 4a). The mean $\theta$ value was $23 \pm 8^{\circ}$ and the largest value was $35^{\circ}$ (central Aleutians). Outliers with exceptionally steep dips, however, were observed for the incipient subduction zones of Cotobato $\left(51^{\circ}\right)$, Wetar $\left(58^{\circ}\right)$ and Flores $\left(71^{\circ}\right)$. It is possible that these zones have not yet reached a steady state configuration. Their positions are highlighted in Figures 4 and 5 for completeness; however, they are excluded from the following statistical analysis.

[35] The average global view (Figure 6) shows that $U$ exhibited a limited variability with respect to $D$, especially in depth $\left(U_{z}\right.$ mean location was at $11 \pm$ $4 \mathrm{~km}$, whereas $D_{z}$ was at a depth of approximately $51 \pm 9 \mathrm{~km})$. In turn, $W_{z}$ accounted mainly for the variability in $D_{z}\left(R=0.90\right.$ for the $\left[D_{z}, W_{z}\right]$ relation; Figures $3,4 b$, and $4 c$ ).

[36] The geometrical relations between $\theta, W_{z}$ and $W_{x}$ imply that the variability in $W_{x}$ (and $W$ ) is defined by the combined variations in $\theta$ and $W_{z}$ (i.e., $D_{z}$ ). These relations are illustrated in Figure 6 using the observation that $U_{z}$ was approximately constant at a $10 \mathrm{~km}$ depth. At first order, $W_{x}$ and $W$ were determined by $\theta(R=-0.81$; Figure 3$)$. In this case, flat geometries allowed for large $W$ values (mean value was $112 \pm 40 \mathrm{~km}$, but values larger than $180 \mathrm{~km}$ were observed for subduction zones such as the Andaman and western Aegean; Figure 4 and Table 1) that were on average $12 \mathrm{~km}$ larger than $W_{x}$ $(R=0.99$; Figure 3$)$. However, this effect was selflimited by the opposite and second-order correlation between $\theta$ and $W_{z}(R=0.46$; Figure 3$)$ so that flat geometries were associated at the same time with large values of $W_{x}$ and small values of $W_{z}$.

\subsubsection{Correlations With Subduction Parameters}

[37] The assessed geometrical parameters were found to be fairly uncorrelated with most of the subduction parameters (IRI mean value was $0.21 \pm$ 0.16), in particular the fore-arc Moho depth, slab age, and absolute plate and trench motions $(|R|<$ 0.20 ; Figure 3). However, significant correlations were observed between the relative plate motions and $\varphi$.

\subsubsection{Location of the Volcanic Arc and the Fore-Arc Moho}

[38] The parameter $D_{x}$ was found to extend up to $65 \pm 20 \%$ of the trench-arc distance, and $W_{x}$ was found to represent $50 \pm 20 \%$ of this distance (Figure 6). A strong relation was observed between these two structural features, and significant correlations were observed between $d_{\text {arc } t}$ and $D_{x}(R=0.67$; Figure 3$)$ or $W_{x}(R=0.60$; Figure 3). However, these parameters were derived from a first-order geometrical control (that is, $R=0.69$ for the $\left[\theta, d_{\text {arc-t }}\right]$ relation and $R=$ 0.69 for the $\left[\theta, D_{x}\right]$ relation; Figure 3 ). 

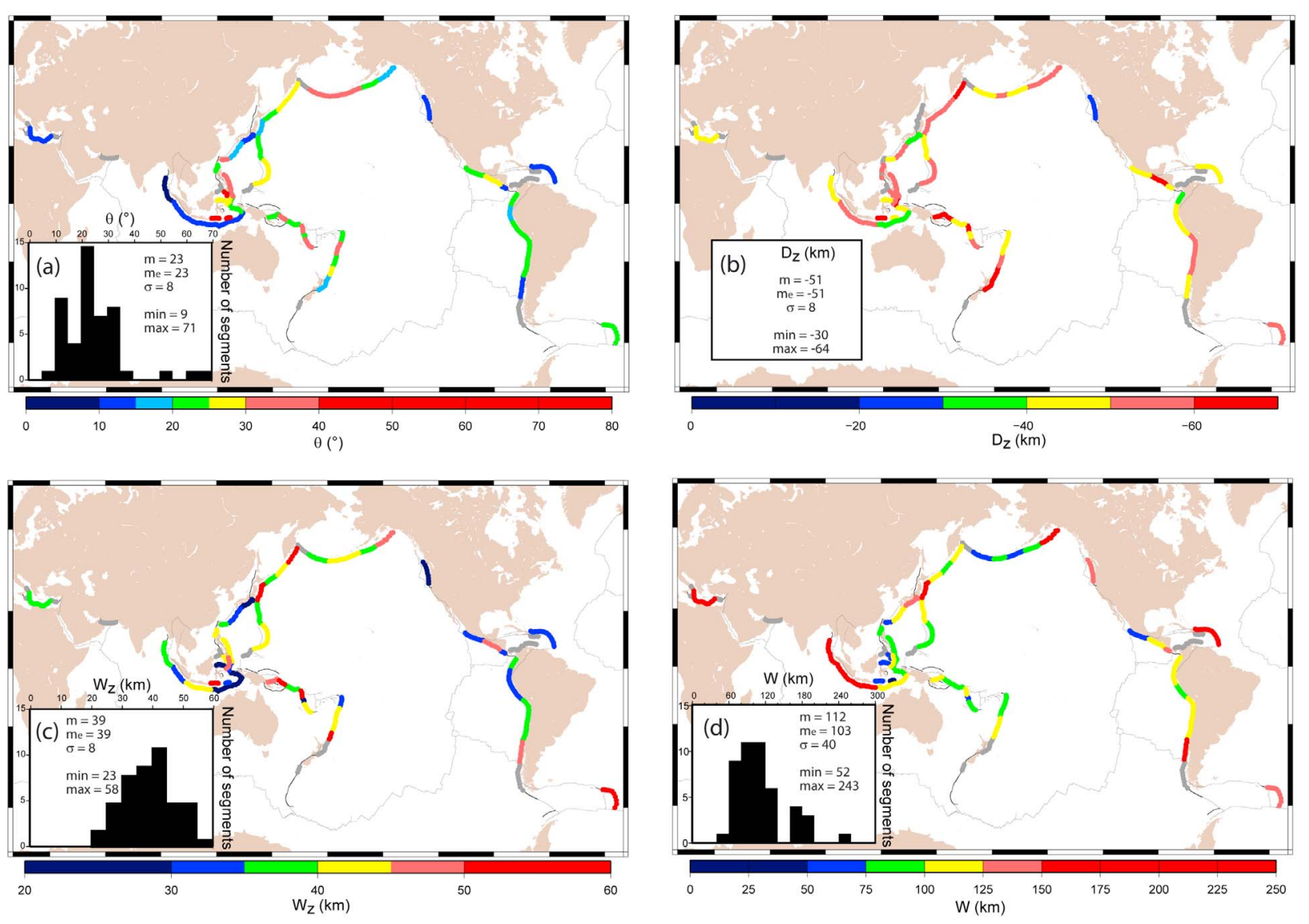

Figure 4. Along-trench variability of the subduction plate interface seismogenic zone geometry. (a) Dip $\theta$, (b) downdip limit of the seismogenic zone $D_{z}$ (the corresponding histogram is in Figure 6), (c) downdip width vertical component $W_{z}$, and (d) downdip width $W$. The gray color refers to segments where $N_{5.5-7.0}<10$ events occurred and were not constrained by local studies. For each parameter, we calculated the mean value $m$, the median value $m_{e}$, the largest value max, the lowest value min, and the standard deviation $\sigma$ (the $[m-\sigma ; m+\sigma]$ interval encompassed $68 \%$ of a given parameter distribution) of each parameter.

[39] The upper plate Moho has often been presented as a structural depth limit for the seismogenic zone [e.g., Ruff and Tichelaar, 1996; Oleskevich et al., 1999]. This hypothesis was tested for the following systems: (1) the whole set of segments, using the upper plate nature as a proxy for the fore-arc Moho depth and (2) for the set of 17 segments for which updated fore-arc Moho depth data were available [Wada and Wang, 2009]. Continental upper plates represent approximately $80 \%$ of the Wada and Wang [2009] database. This proportion reflects the presence of continental upper plates in the complete subduction data set. In intraoceanic subduction zones, the fore-arc Moho is as shallow as approximately $10 \mathrm{~km}$ in depth. However, in continental fore arcs, it is reported at a depth of $34 \pm 11 \mathrm{~km}$. No relation has been found between the Moho depth (or the upper plate nature) and

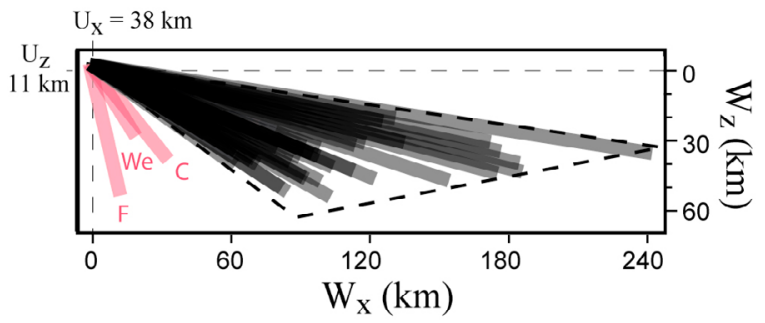

Figure 5. Relation between $\theta, W_{x}$, and $W_{z}$. The seismogenic zone extents of 42 segments with $\mathrm{N}>10$ are represented by gray bars in the $\left[W_{x} ; W_{z}\right]$ space by assuming $U$ to be constant $(38 \mathrm{~km}$ away from the trench and $11 \mathrm{~km}$ deep). Red bars correspond to Wetar, Flores, and Cotobato steep subduction plate interfaces. Trench segment symbols are defined as in Table 1. 


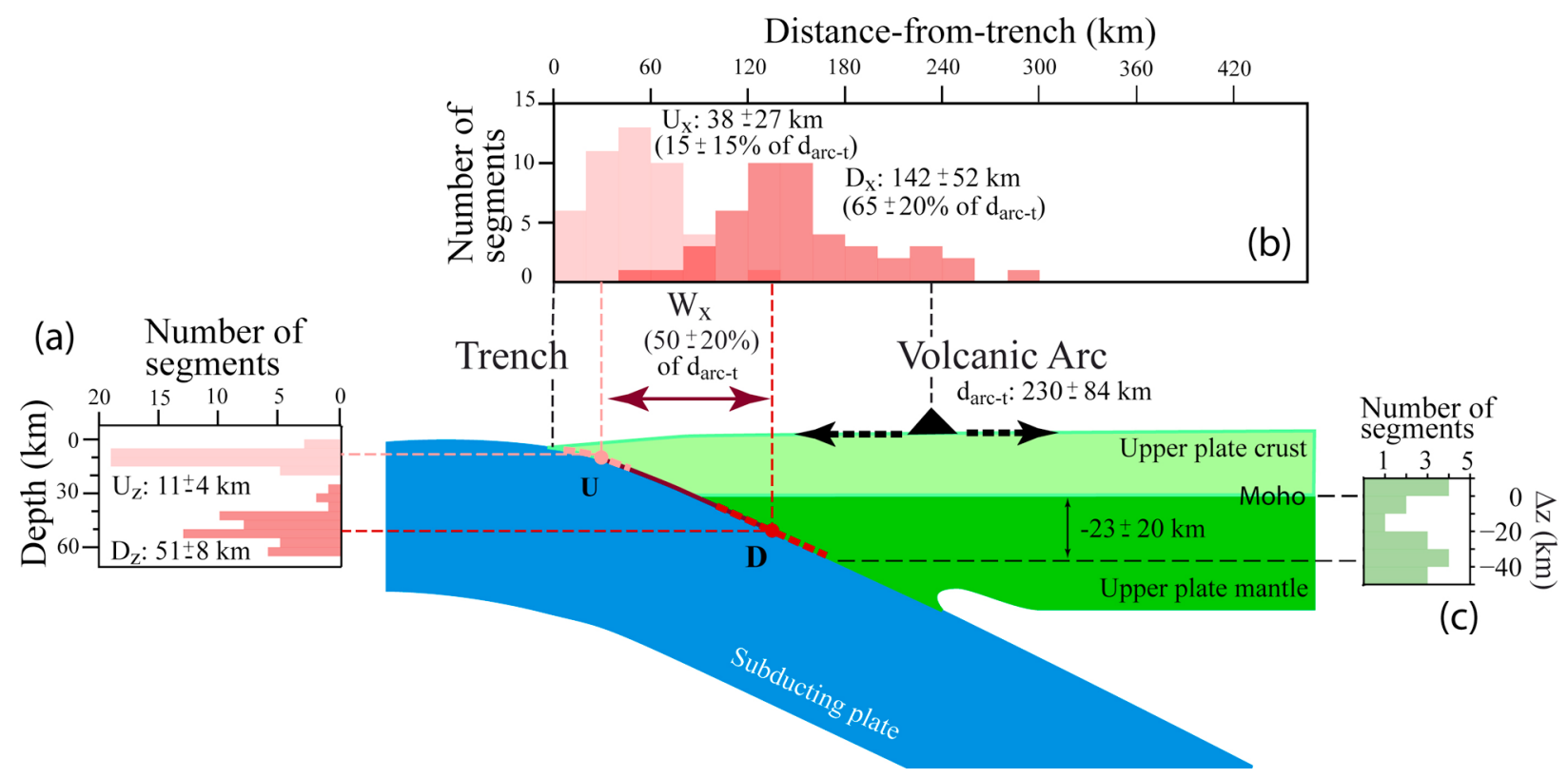

Figure 6. Global variability of the seismogenic zone limit positions. (a) Depth limit histograms. (b) Distanceto-trench limit histograms. Mean values and standard deviations are given in $\mathrm{km}$ and as percentages of the trenchvolcanic arc distance (in parentheses). (c) Histogram of the relative position of the seismogenic zone downdip depth limit with respect to the fore-arc Moho depth $(\Delta z)$ for 17 segments. The Moho depth data set is from Wada and Wang [2009]. By convention, in Figure 6, the Moho is fixed at a depth of $35 \mathrm{~km}$. This depth is representative of a mean continental fore-arc Moho. Symbols are defined as in the notation section.

$D_{z}, W_{z}$ or any other seismogenic zone geometry parameter. In fact, $70 \%$ of the seismogenic zones extend more than $10 \mathrm{~km}$ below the upper plate Moho (i.e., in contact with the fore-arc mantle; Figure $6 \mathrm{c}$ ). The mean $\Delta \mathrm{z}$ value was $-23 \pm 20 \mathrm{~km}$. The largest $\Delta z$ values have been observed for intraoceanic subductions and reach $-40 \mathrm{~km}$.

\subsubsection{Subduction Velocity}

[40] The relative plate motions $v_{s}$ and $v_{c}$ exhibited some of the most significant correlations with the subduction interfaces geometrical parameters. As the subduction velocity increased, the values of $\theta, D_{z}$ and $W_{z}$ increased and the value of $W$ decreased. However, the correlations with $\theta(R=0.55$; Figure 7a) and $W(R=-0.45$; Figure $7 \mathrm{~d})$ and, to a lower extent, with $W_{z}(R=0.30$; Figure $7 \mathrm{c})$ and $D_{z}(\mathrm{R}=$ -0.34 ; Figure $7 \mathrm{~b}$ ) were improved by $25 \%-50 \%$ if the fastest subduction zones (northern Tonga and northern New Hebrides) were removed from the statistical analysis or if second-order polynomial regressions were used. This finding hints at possible inversions in the tendencies over $v_{s}$ values of approximately $80-150 \mathrm{~mm} \mathrm{yr}^{-1}$. The parameter $U_{z}$ was found to be uncorrelated with $v_{s}(\mathrm{R}=$ -0.04 ; Figure $7 b$ ).

\subsubsection{Thermal Parameter of the Subducting Plate}

[41] The thermal parameter exhibited a significant correlation coefficient with the subduction interfaces geometrical parameters. The values of $D_{z}$, $W_{z}$ and $\theta$ increased as the slab became colder (that is, $\varphi$ became lower) whereas $W_{x}$. However, the correlations with $\theta(R=0.49$; Figure $7 \mathrm{e}), D_{z}(\mathrm{R}=$ -0.42 ; Figure $7 \mathrm{f})$ and $W_{z}(R=0.40$; Figure $7 \mathrm{~g})$ and, to a lower extent, with $W(R=-0.30$; Figure $7 \mathrm{~h})$ were improved by $25 \%-70 \%$ if northern Tonga and northern New Hebrides segments were removed from the statistical analysis or if second-order polynomial regressions were used. This finding hints at possible inversions in the tendencies over $\varphi$ values of approximately $4500 \mathrm{~km}$. There was no correlation between $U_{z}$ and $\varphi(\mathrm{R}=-0.23$; Figure $7 \mathrm{~b})$.

\subsection{Mechanical Behavior of the Subduction Interface Seismogenic Zone}

\subsubsection{Global Variability}

[42] For the time period from 1976 to 2007, a total of $3283 M_{w} \geq 5.5$ plate interface earthquakes have been identified, $4.2 \%$ of which were $M_{w} \geq 7.0$ events. For the time period from 1900 to 2007, a 

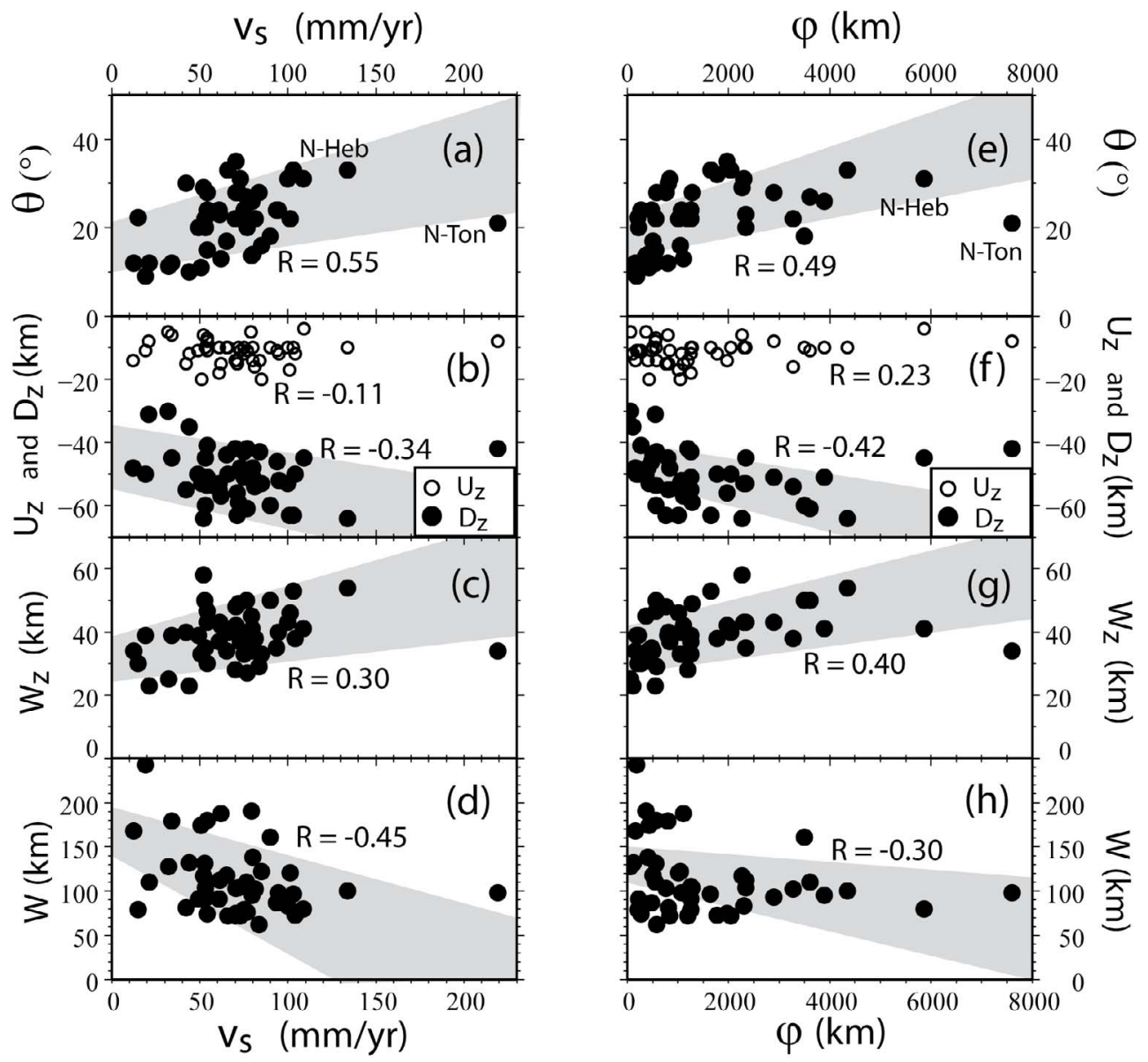

Figure 7. Relationships between $(\mathrm{a}-\mathrm{d})$ the subduction velocity $v_{s}$ or $(\mathrm{e}-\mathrm{h})$ the thermal parameter $\varphi$ with the seismogenic zone $\operatorname{dip} \theta$ (Figures $7 \mathrm{a}$ and $7 \mathrm{e}$ ); $U_{z}$ and $D_{z}$, the updip and downdip depth limits of the seismogenic zone, respectively (Figures $7 \mathrm{~b}$ and $7 \mathrm{f}$ ); the vertical extent of the seismogenic zone $W_{z}$ (Figures $7 \mathrm{c}$ and $7 \mathrm{~g}$ ); and the downdip width of the seismogenic zone $W$ (Figures $7 \mathrm{~d}$ and $7 \mathrm{~h}$ ). Trench segment symbols are defined as in Table 1. N-Ton and N-Heb segments were not considered in the linear regressions. Gray shaded areas represent the main trend, as constrained by the $95 \%$ confidence level interval for the $y$ intercept and the slope determined by linear regression analysis.

total of 726 large subduction plate interface events were considered. Among these, 49 were $M_{w} \geq 8.0$ earthquakes and 13 were $M_{w} \geq 8.5$ events. The distributions of the seismic rate (Figure 8a) and largest magnitude events (Figure 8b) were heterogeneous along the trench segments.

[43] The mean $\tau$ value was approximately 210 events when normalized to 100 years and $1000 \mathrm{~km}$ of trench length (Figure 8a), but the distribution was lognormal. In other words, the lowest rates were the most widely represented $(65 \%$ of the segments had $\tau$ values lower than 200 events). The largest values reached 1000 events (e.g., north Kermadec, Bougainville and New Britain; Table 1).

[44] The $M_{\max }$ mean value was $7.8 \pm 0.7$, and $75 \%$ of the segments experienced at least one $M_{w} 7.5$ event. The south Chile event $\left(M_{w} 9.5,1960\right)$ was the largest ever observed. The 14 recorded $M_{w} \geq$ 8.5 earthquakes were confined to only four different trench systems: South America (5 events), Japan-Kuril (3 events), Aleutians-Alaska (3 events) and Sunda (3 events) which also experienced $28 \%$, $22 \%, 10 \%$ and $8 \%$, respectively, of the 50 subduction interface $M_{w} \geq 8.0$ earthquakes.

[45] The seismic moment released by the subduction interface during the time period of 1900-2007 was approximately $6.9 \times 10^{23} \mathrm{~N} \cdot \mathrm{m}$, representing $80.2 \%$ of the total seismic moment released worldwide over all geodynamical environments. The value of $M R R$ was variable along the trenches (Figure $8 \mathrm{c}$ ), and its mean value was $10^{22} \mathrm{~N} \cdot \mathrm{m}$ when normalized to 100 years and $1000 \mathrm{~km}$ of trench 



Figure 8. Along-trench variability of the subduction plate interface seismogenic zone seismic activity. (a) Seismic rate $\tau$, (b) potential size of earthquakes $M_{\max }$, (c) $M_{M R R}$, and (d) seismic coupling coefficient $\chi$. The gray color refers to segments where no thrust event was recognized during the 1900-2007 time period. Symbols are defined as in Figure 4.

length $\left(M_{M R R}=8.2 \pm 0.6\right)$. The seismic slip rates associated with the moment rates for most trench segments were low with respect to their subduction velocities, and the seismic coupling coefficients were generally low (Figure 8d). The parameter $\chi_{(n)}$ exhibited a similar distribution; however, it was shifted slightly toward higher values, as $v_{s(n)}$ was lower than $v_{s}$. The mean $\chi$ value was 0.25 , and $56 \%$ of the segments had values lower than 0.2 .

[46] For a given trench segment, $M R R$ and $\chi$ were functions of both $M_{\max }$ and $\tau$. However, the largest $M R R$ values were controlled by the occurrence of $M_{w} \geq 8.0$ earthquakes, rather than by the number of events. Thus, the sole south Chile event $\left(M_{w} 9.5\right.$, 1960) represents $33 \%$ of the seismic energy released along the subduction interface. As a consequence of the $M_{M R R}$ dependence on $M_{\max }, \chi$ was also well correlated with $M_{\max }(R=0.74$; Figure 3). Further, the occurrence of at least one $M_{w} \geq 8.5$ earthquake is a necessary condition for a given segment to have a fully coupled interface $(\chi \geq 0.8$; $12 \%$ of the cases). In fact, the segments where the largest events occurred were those where the largest $M R R$ and $\chi$ were measured. Because $M_{\max }$ was found to highly influence the moment rate and extent of seismic coupling, we focused our analysis on the variability in $M_{\max }$.

\subsubsection{Correlations With Subduction Parameters}

[47] The mechanical parameters were fairly uncorrelated with most of the subduction parameters (IRI mean value was $0.21 \pm 0.16)$. However, except for $\chi$, significant correlations were observed with the subduction velocity $(0.30<|R|<0.60$; Figure 3$)$. Seismic rate was the only parameter that correlated with the subducting plate thermal state $(\mathrm{R} \approx 0.60$; Figure 3). 


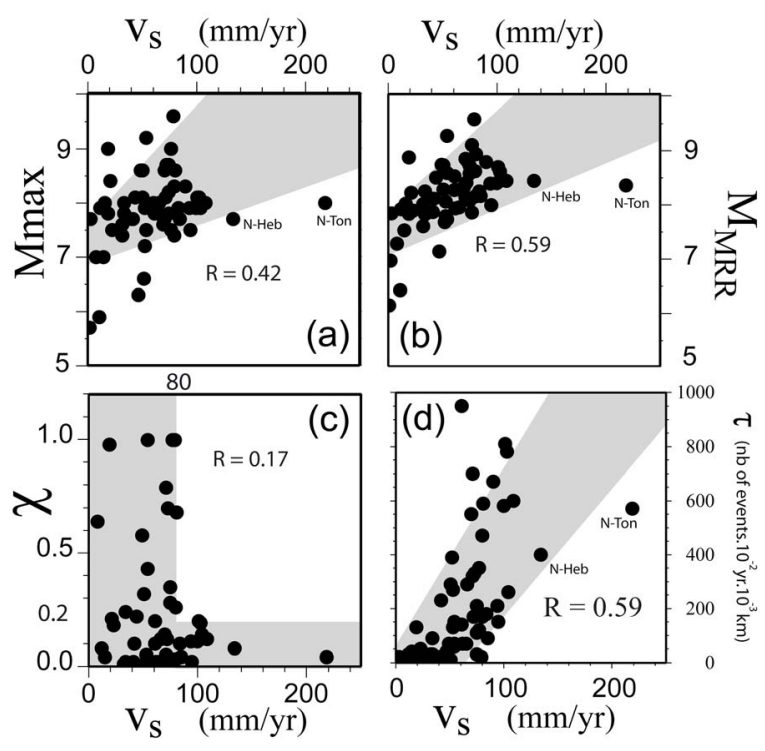

Figure 9. Relation between the subduction velocity $v_{s}$, given in $\mathrm{mm} \mathrm{yr}^{-1}$, and (a) $M_{\max }$, (b) $M_{M R R}$ (c) $\chi$, and (d) $\tau$. N-Ton and N-Heb segments were not considered in the linear regressions. Gray shaded areas represent the main trend, as constrained by the $95 \%$ confidence level interval for the $y$ intercept and the slope determined by linear regression. Trench segment symbols are defined as in Table 1.

\subsubsection{Subduction Velocity}

[48] Among all the subduction parameters, $v_{s}$ and $v_{s n}$ were the most significantly correlated with the mechanical parameters and, in particular, the seismic rate $(R=0.61$; Figure $9 \mathrm{~d})$. Better correlation coefficients were observed when taking into account the cumulated seismic moments that were released by all of the events registered in the segment $\left(R=0.50\right.$ for $\left[M_{M R R} ; v_{s}\right]$ relation; Figure 3$)$, rather than only the moment released by the largest event $\left(R=0.34\right.$ for $\left[M_{\max } ; v_{s}\right]$ relation; Figure 3$)$. No correlation was observed between $\chi$ and the subduction velocity $(R=0.04$; Figure 3$)$.

[49] The relationships between $v_{s}$ and the mechanical parameters were not strictly linear and the correlations were improved when northern Tonga and northern New Hebrides were not considered. Indeed, $\tau$ increased with increasing $v_{s}$ slowly for the low-velocity plates $\left(v_{s}<80 \mathrm{~mm} \mathrm{yr}^{-1}\right)$ and sped up for the higher-velocity plates (Figure 9d). An exponential regression only moderately improved the correlation coefficient (approximately 6\%). The largest $M_{\max }$ (or $M_{M R R}$ ) values were not associated with the fastest subduction zones (Figures $9 \mathrm{a}$ and $9 \mathrm{~b}$ ). For example, northern Tonga $\left(v_{s}=220 \mathrm{~mm} \mathrm{yr}^{-1}\right)$, had never experienced an $M_{w}>8.1$ interface event during the time span of the seismic records used in this work. In fact, $M_{\max }$ (or $M_{M R R}$ ) increased linearly with the subduction velocity, up to approximately $80 \mathrm{~mm} \mathrm{yr}^{-1}$. For larger velocity values, $M_{\max }$ and $M_{M R R}$ seemed to gradually decrease $\left(M_{\max } \leq 8.1\right.$ and $\left.M_{M R R} \leq 8.8\right)$. A second-degree polynomial regression improved the correlation of these parameters with $v_{S}(R=0.42$ and 0.59 for $M_{\max }$ and $M_{M R R}$, respectively). A strong contrast was also found between the slowest and fastest subduction zones in terms of seismic coupling (Figure 9c). All of the subduction zones with $v_{s}<80 \mathrm{~mm} \mathrm{yr}^{-1}$ had $\chi>0.2$. In contrast, for larger velocities, all of the subduction zones exhibited low seismic coupling $(\chi<0.2)$.

[50] Among the other kinematical parameters, $\tau$ was also reasonably correlated with $V_{\text {sub }}(R=0.57$; Figure 3), but not with $V_{u p}$ or $V_{t}$. $V_{u p}$, and $V_{t}$ also exhibited negligible correlations with $M_{\max }(R \approx$ -0.15 ; Figure 3 ). Advancement of the upper plate did not systematically promote $M_{w} \geq 8.5$ earthquakes, and upper plate retreat was not always associated with a low $M_{\max }$. In fact, the fastest upper plates (or trenches) were never associated with $M_{w} \geq 8.5$ earthquakes, as has been argued in previous studies [e.g., Uyeda and Kanamori, 1979; Conrad et al., 2004]. Events with $M_{\max } \geq 8.5$ were limited to relatively fixed trenches and upper plates that had velocities ranging between $-30 \mathrm{~mm} \mathrm{yr}^{-1}$ and $50 \mathrm{~mm} \mathrm{yr}^{-1}$ in the Pacific hot spot reference frame HS3 [Gripp and Gordon, 2002].

\subsubsection{Thermal Parameter of the Subducting Plate}

[51] The subduction velocity was not able to explain the diversity in $M_{\max }$, and high scattering remained inside the general trend. To explain this scattering, second-order parameters should be involved. Ruff and Kanamori [1980] observed a negative correlation between $M_{\max }$ and the slab age. They argued that a large $M_{\max }$ can be explained by the combined influence of a young subducting plate and fast subduction velocity. However, in the revised data set obtained here (Figure 10), no significant correlation was observed between the $M_{\max }$ and plate age ( $R=0.05$; Figure 3 ). Thus, it is necessary to review the theory proposed by Ruff and Kanamori [1980]. Recently, a similar conclusion was reached by Stein and Okal [2007] and Gutscher and Westbrook [2009] thanks to a detailed study of past $M_{w} \geq 8.0$ earthquakes [e.g., Clague, 1997; Satake and Atwater, 2007] and the occurrence of the peculiar recent 2004 Sumatra event [Lay et al., 2005]. The thermal parameter $\varphi$, which is an alternative way to combine $v_{s}$ and the plate age influence, was not 




Figure 10. Relation between the subduction velocity $v_{s}$, slab age, and $M_{\max }$. Dashed lines are theoretical $M_{\max }$ limits, as estimated by Ruff and Kanamori [1980].

correlated with $M_{\max }(R=0.09$; Figure 3$), M_{M R R}$ $(R=-0.10$; Figure 3$)$ or $\chi(R=0.18$; Figure 3$)$. Despite the seismic rate was uncorrelated with the slab age ( $R=0.17$; Figure 3$)$, it was found that large $\varphi$ (i.e., cold slabs) promote a large number of plate interface earthquakes $(R=0.54$; Figure 3$)$.

\subsubsection{Upper Plate Nature}

[52] A strong contrast was observed between the plate interface mechanical behavior of intraoceanic subduction zones and those associated with continental upper plates (Figure 11a). All of the observed $M_{w} \geq 8.5$ events were associated with continental upper plates (the $M_{\max }$ mean value was $7.9 \pm 0.7$ ). However, the largest event experienced at an intraoceanic plate interface during the last century was only 8.1 (the $M_{\max }$ mean value was $7.5 \pm 0.6$ ). The same trend was observed with $\chi$ (Figure 11b) and $M_{M R R}$. The oceanic upper plates were associated with a low seismic moment release and with low seismic coupling values $(\chi \leq 0.2)$. No particular relationship was observed with $\tau$ (Figure 11c).

\subsubsection{Upper Plate Strain}

[53] Based on the study by Uyeda and Kanamori [1979], it is commonly thought that $M_{w} \geq 8.5$ earthquakes are associated with compressive upper plate strain and that $M_{\max }$ decreases when the strain becomes extensive. However, the correlation between $M_{\max }$ and UPS was found to be low $(R=$
0.19 ; Figure 3 ), and as previously noticed by Hayes and Conrad [2007], $M_{w} \geq 8.5$ earthquakes were preferentially associated with a neutral UPS (Figure 11b). The compressive back arcs exhibited intermediate values $\left(M_{\max } \leq 8.7\right)$, and high values were never observed where back-arc spreading or rifting occurred $\left(M_{\max } \leq 8.1\right)$. The Sumatra event (2004; $\left.M_{w}=9.0\right)$ was not an exception to this trend. Even when the ruptured area extended from northern Sumatra up to the Andaman extensive margin, the earthquake nucleation occurred in an area characterized by a neutral tectonic regime.

[54] Similar trends were observed for $\chi$ and $M_{M R R}$. In particular, the largest $\chi$ values were preferentially associated with neutral back-arc deformations (Figure 11c), whereas compressive back arcs showed intermediate values. Large values were never observed where back-arc spreading or rifting was found to occur $(\chi \leq 0.20)$. No particular relationship was observed with $\tau$ (Figure 11f).

\subsection{Relationships Between the Mechanical Behavior and the Subduction Fault Geometry}

\subsubsection{Downdip Width and Dip of the Seismogenic Zone}

[55] Theoretically, the earthquake magnitude potential of a given trench segment should increase with



Figure 11. Relations between the upper plate nature and (a) $M_{\max }$, (b) the seismic coupling coefficient $\chi$, and (c) the seismic rate $\tau$, as well as the relation between the upper plate strain and (d) $M_{\max }$, (e) the seismic coupling coefficient $\chi$, and (f) the seismic rate $\tau$. Respective percentages of the oceanic and continental upper plates, as well as percentages of the extensional, neutral, and compressive UPS, are given. 

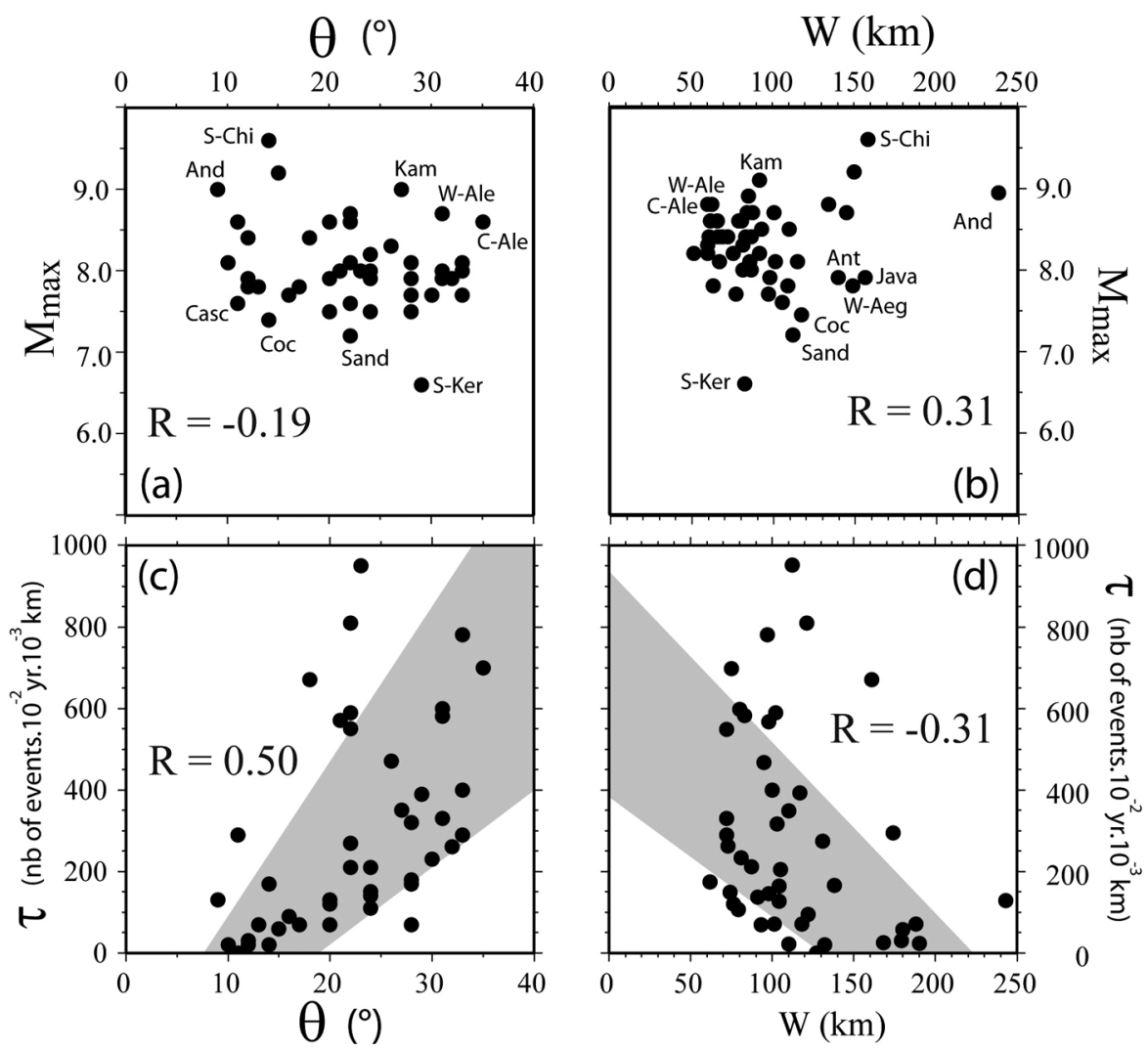

Figure 12. Relation between $M_{\max }$ and (a) the dip of the seismogenic zone $\theta$ and (b) the seismogenic zone downdip width $W$, as well as the relationship between the seismic rate $\tau$ and (c) the dip and (d) the downdip width of the seismogenic zone. Gray shaded areas represent the main trend, as constrained by the $95 \%$ confidence level interval for the $y$ intercept and the slope determined by linear regression. Trench segment symbols are defined as in Table 1.

the surface of the potential rupture area and, in particular, with the downdip width of the coupled zone. Correlations of $M_{\max }$ with $\theta(R=0.32$; Figure 12a) and $W(R=-0.19$; Figure $12 \mathrm{~b})$ were found to be weak. The downdip width was not the key parameter in determining the occurrence of $M_{w} \geq 8.5$ earthquakes. This observation was confirmed by the fact that some of the segments that expressed $M_{w} \geq$ 8.5 earthquakes were associated with steep and/or narrow seismogenic zones (e.g., central Aleutians: $\theta=35^{\circ}, W=75 \mathrm{~km}$; Table 1). Moreover, despite the fact that $M_{w} \geq 8.5$ earthquakes were often associated with the flattest and widest seismogenic zones, some segments with similar seismogenic zone geometries did not express any $M_{w} \geq 8.5$ events during the last century (e.g., Antilles, Java and the western Aegean; Table 1).

[56] As with $M_{\max }$, similar trends were observed for $M_{M R R}$ and $\chi$. However, better correlations were observed for the seismic rate. For example, the value of $\tau$ was found to increase with $\theta(R=0.50$; Figure 12c) and decrease with $W(R=-0.31$; Figure $12 \mathrm{~d})$.

\subsubsection{Along-Trench Variability of the Subduction Interface Mechanical Behavior}

[57] The values of $\tau$ and $M_{\max }$ were uncorrelated at first order $(\mathrm{R}=0.25$; Figure 3$)$. However, noteworthy characteristics of the $\left[M_{\max } ; \tau\right]$ relation and for the occurrence of $M_{w} \geq 8.5$ events were observable when focusing on their variability along isolated trench systems. The longest subduction zones (i.e., Sunda, South America, AleutiansAlaska and NE Japan-Kuril) expressed strong lateral variabilities from their edges to centers with respect to their plate interface mechanical parameters, namely in terms of $\tau$ and $M_{\max }$ (Figures 8a and $8 \mathrm{~b}$ ). Figure 13a shows how $\tau$ varied along the half-trench systems, from one slab edge toward the slab center (for each trench system, the slab center was defined as the maximum $\tau$ value location). Similarly, Figure 13b shows the $M_{\max }$ alongtrench variations for the half-trench systems (the slab center was then determined by the minimum $M_{\max }$ value locations). 




Figure 13. Along-trench variations of (a) seismic rate $\tau$ and (b) $M_{\max }$. Along-trench variations are plotted for half-trench systems. For each half-trench system, distances are expressed as percentages of the distance between the slab edge and the largest $\tau$ value position (Figure 13a) or the lowest $M_{\max }$ value position (Figure 13b). Black marks on the insets indicate the along-trench position of the largest $\tau$ value (Figure 13a) and the lowest $M_{\max }$ value (Figure 13b) for each trench system. Variations are plotted from the slab lateral edges, where the lowest $\tau$ and largest $M_{\max }$ values are located, toward the largest $\tau$ and lowest $M_{\max }$ positions, which are located in the vicinity of the geographical centers of the trench system. Trench systems are as follows: blue, South America (Colombia and Chilean Triple Junction (CTJ) edges); orange, Aleutians-Alaska (western Aleutians and eastern Alaska edges); green, Sunda (Andaman and Timor edges); and red, NE Japan-Kuril. The NE Japan-Kuril trench system is only represented by the Kamchatka edge. The Marianas edge is excluded here because of strong changes in the kinematical conditions from Japan (Pacific-Amur convergence) to the southern Marianas (Pacific-Philippine Sea convergence).

[58] It appeared that the variability was not randomly organized. Comparison of the contrast in slab edges with slab centers yielded opposite trends when considering $\tau$ or $M_{\max }$. The lowest $\tau$ values were located near slab edges, and they progressively increased toward slab centers (Figure 13a). Conversely, the largest $M_{\max }$ occurred near slab edges and progressively decreased toward slab centers (Figure 13b). Thus, large seismic energy releases in a few large events at slab edges contrasted with slab centers, where lower seismic energy levels were obtained in numerous events of relatively smaller sizes. As a result, slab edges appeared much more seismically coupled than the centers.

\section{Discussion}

[59] An original database was built to describe the subduction interface seismogenic zone variability in terms of geometry and mechanical behavior, as well as to compare these constraints to other subduction parameters, revisiting some empirical laws that were obtained in previous studies [e.g., Ruff and Kanamori, 1980; Kanamori, 1986; Jarrard, 1986; Tichelaar and Ruff, 1993; Pacheco et al., 1993; Conrad et al., 2004]. Correlation coefficients were often low (that is, the $\mathrm{R}$ value was $0.25 \pm 0.21$ ), and the lack of a strong relationship between parameters emerged from the statistical analysis. This complexity in the statistical bivariant relations between collected parameters reflects, to some extent, the intricate subduction related physical processes. Subduction was settled by the interplay of numerous possible variables so that a single parameter was never able to explain the whole diversity observed at subduction interfaces. However, the statistical scattering was also largely related to the limited time span and accuracy of the collected seismic observations, such that most of the estimated parameters (e.g., $D_{z}, W$, $M_{\max }$ and $\chi$ ) have to be considered as lower bounds; thus, it was necessary to approach their interpretation with caution. As an example, the instrumental record gives low values for the seismicity parameters of the Cascadia subduction $\left(M_{\max }=7.6\right.$ and $\chi=0.01$; Table 1$)$, whereas there was evidence for a $M_{w}=9.0$ earthquake in that location approximately 300 years ago [Satake et al., 2003]. Under such conditions, it is unfair to discuss accurate empirical equations between these parameters. It is, however, possible and useful to discuss the most reliable statistical trends and the most meaningful physical relations.

\subsection{Global Variability}

\subsubsection{Geometry}

[60] Our analysis confirms that most of the seismogenic zones exhibited shallow dipping geometries (Figures 4 and 5) with dip angles $(\theta)$ between 


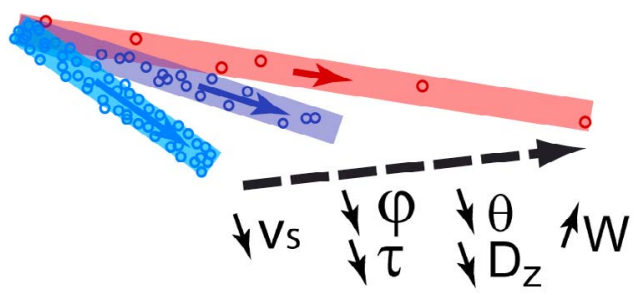

Figure 14. Relationships between the subduction velocity and seismogenic zone physical characteristics.

$10^{\circ}$ and $35^{\circ}$ and a mean dip value at $23 \pm 8^{\circ}$. The seismogenic zone downdip width $(W)$ distribution spanned over a wide range, with most of the values lying between $60 \mathrm{~km}$ and $180 \mathrm{~km}$ and with a mean downdip extent of $112 \mathrm{~km} \pm 40 \mathrm{~km}$. These estimates are consistent with previous work by Pacheco et al. [1993] ( $W=95 \mathrm{~km} \pm 27 \mathrm{~km})$, considering the adopted limits of the different data sets, selection criteria and computation methods. Our estimates for the downdip limit depth $\left(D_{z}=\right.$ $51 \mathrm{~km} \pm 8 \mathrm{~km}$; Figure 6) are also consistent with that of Pacheco et al. [1993] $\left(D_{z}=49 \mathrm{~km} \pm 11 \mathrm{~km}\right)$, but they were on average $10 \mathrm{~km}$ deeper than those found by Tichelaar and Ruff [1993], who used a smaller set of subduction zones and constrained the depth limit by considering only the rupture area of large events. Though the fore-arc Moho has often been presented as a structural depth limit for the seismogenic zone [e.g., Ruff and Tichelaar, 1996], we found that $70 \%$ of the seismogenic zones extended more than $10 \mathrm{~km}$ below the fore-arc Moho, lying in contact with the fore-arc mantle (Figure 6). Because the lower aseismic limit of the seismogenic zone has often been explained as being caused by mantle serpentinization [e.g., Reinen et al., 1992; Hyndman et al., 1997; Moore et al., 1997], our results suggest that the extent of serpentinization of the mantle wedge may differ locally [e.g., Seno, 2005].

\subsubsection{Mechanical Parameters}

[61] In the present study, we confirmed that the seismic potential of the subduction plate interface was large (the $M_{\max }$ and $M_{M R R}$ mean values were $7.8 \pm 0.7$ and $8.2 \pm 0.6$, respectively; Figure $4 \mathrm{~b}$ ) with respect to other geodynamical environments [e.g., Pacheco and Sykes, 1992]. The plate interface released $80 \%$ of the worldwide seismic moment. Regardless of the subduction conditions, this was able to generate large earthquakes $(75 \%$ of the segments experienced at least one $M_{w} 7.5$ event).
[62] In agreement with previous studies [e.g., Pacheco et al., 1993; McCaffrey, 1997a], the average seismic coupling coefficient was generally found to be low $(\chi=0.25 \pm 0.30$; Figure 8d), indicating that the slip over the last 107 years was either mostly aseismic or that the strain was accumulating. However, Bird and Kagan [2004] found a higher average seismic coupling $(\chi=0.69)$, probably due to their different approach; the shallow seismicity was cumulated over all subduction zones, leading to an overestimation of the seismic coupling due to the following reasons: (1) there was no distinction between the interface and intraplate events and (2) at subduction zones where $M_{w} \geq 8.5$ events occurred, $\chi$ was often larger than 1.0 , which is physically impossible but not detectable in the Bird and Kagan [2004] view (e.g., $\chi=3.5$ in southern Chile; Table 1). In our work, such values were fixed at 1.0.

\subsection{Subduction Interface Variability and Subduction Velocity}

\subsubsection{Geometry and Seismic Rate}

[63] Among all the subduction parameters, $v_{s}$ and $\varphi$ were the most significantly correlated with the plate interface parameters (Figures 7 and 9), especially with the geometry and seismic rate $(0.40<$ $|R|<0.60$; Figure 3). These correlations depict a coherent portrait of the seismogenic zone variability, in which fast and cold subduction zones produced a large number of moderate earthquakes over a narrow, deep and steeply dipping seismogenic interface (Figure 14). Physically, this means that the subduction velocity $v_{s}$ may have affected the seismogenic zone behavior through a combination of stress accumulation and temperaturerelated processes (the faster a slab penetrates into the hot mantle, the slower it warms; that is, fast subduction zones are associated with cold slabs).

[64] The increase of $D_{z}$ and $W_{z}$ with $v_{s}$ may be mainly explained by temperature-related processes, as supported by the improved correlation when $\varphi$, rather than $v_{s}$, was considered. Thus, in fast and cold subduction zones, the frictional properties of the plate interface are likely maintained at large depths. As the seismogenic zone often ends in the fore-arc mantle, the process could imply slab dehydration. This confirms the theory put forth by Wada and Wang [2009], which highlights how slab dehydration occurs deeper in the mantle in cold compared to warm subduction zones. This results in a lower amount of fore-arc mantle serpentinization and a 
greater tendency for the subduction interface to be seismogenic. The fundamental role that the mechanical contribution can play in the subduction interface seismic behavior has also to be considered to explain the fact that the Moho falls above the downdip limit of the seismogenic zone (F. Corbi et al., Seismic variability of subduction thrust faults: Insights from laboratory models, submitted to Journal of Geophysical Research, 2010). In contrast with our observations, Pacheco et al. [1993] did not find any significant dependence of $\theta$ or $W$ on subduction velocity. The improved and increased earthquake records adopted in this study are likely the key to explaining such differences.

[65] The positive exponential correlation observed between $v_{s}$ and $\tau$ (that is, $\tau$ increased slowly for sluggish plates and sped up for fast plates; Figure 9d) is coherent with the Gutenberg and Richter [1954] recurrence law, confirming a common feature of frictional dynamics observed in laboratory experiments [e.g., Baumberger et al., 1994; Corbi et al., submitted manuscript, 2010] and theoretical calculations of fault slip rates [Molnar, 1979; McCaffrey, 1997b]. Moreover, this observation is consistent with the nonlinear relation found by Bird et al. [2009] between earthquake production and relative plate velocity in subduction zones (slower subduction zones with $v_{s} \leq 66 \mathrm{~mm} \mathrm{yr}^{-1}$ are found to represent only $20 \%$ of earthquake productivity and $35 \%$ of the cumulative tectonic moment rate). The positive correlation between $\tau$ and $\varphi$ opens the possibility of a significant influence from additional temperature-related processes (low temperatures may favor unstable sliding of the plate interface).

\subsubsection{Largest Observed Magnitudes, Moment Release, and Seismic Coupling}

[66] The relationships between $v_{s}$ and $M_{\max }, M_{M R R}$ and $\chi$ were difficult to interpret because the period record analyzed was shorter than the recurrence time of most $M_{w} \geq 8.5$ earthquakes. On the one hand, this implies uncertainties in the observed trend that could partly explain the data scattering. On the other hand, the recurrence time of $M_{w} \geq 8.5$ earthquakes is known to be a function of $v_{s}$ (see Gutscher and Westbrook [2009] for a review). It is thus possible that the observed trend is just a probabilistic consequence of the [recurrence time; $v_{s}$ ] relation (that is, the probability for a $M_{w} \geq$ 8.5 earthquake to be expressed is larger during a given time period for fast subduction than for slow subduction) and it may disappear on a larger time scale. Following a similar hypothesis, McCaffrey
[2008] argued that every subduction zone in the world is able to generate $M_{w} \geq 8.5$ earthquakes, and their occurrence should just be a question of time.

[67] The subduction velocity is, at first order, positively correlated with $M_{\max }(R=0.42)$ and $M_{M R R}$ $(R=0.59)$ (Figures 9a and 9b), as expected from the Gutenberg and Richter [1954] recurrence law. Better correlations were observed for the $\left[v_{s} ; M_{M R R}\right]$ relationship than for the $\left[v_{s}, M_{\max }\right]$ relationship because, as a consequence of the Gutenberg and Richter [1954] recurrence law, the cumulated seismic moment is much more representative of the long-term moment rates than $M_{\text {max }}$. Indeed, as the time interval for the available seismic data is short, the largest possible events have likely not been observed yet in every subduction zones, especially the slowest ones, whereas lower size events are more frequent. The seismic coupling $\chi$ was found to be extremely low and uncorrelated with the subduction velocity $(R=0.17$; Figure 9c), confirming the observation of Pacheco et al. [1993]. This proves that, on the 1 century time scale, the seismic potential is far from being fully expressed in most subduction zones.

[68] Relations with $v_{s}$ appeared to be nonlinear. Correlation coefficients were improved when secondorder polynomial regressions were applied. Though only a few segments reached such velocities, from approximately $80 \mathrm{~mm} \mathrm{yr}^{-1}$, the trend was inverted and $M_{\max } / M_{M R R}$ decreased with $v_{s}$. As a result, during the 1900-2007 time window explored in the present study, the largest earthquake magnitudes were not associated with the fastest subduction zones, but rather with zones moving at speeds of $20<v_{s}<80 \mathrm{~mm} \mathrm{yr}^{-1}$. Moreover, none of the $v_{s}>$ $80 \mathrm{~mm} \mathrm{yr}^{-1}$ subduction zones (e.g., northern Tonga; $v_{s}=220 \mathrm{~mm} \mathrm{yr}^{-1}$; Table 1) had experienced $M_{w}>$ 8.1 events. This yielded direct consequences on the $\chi$ distribution (Figure 9c). The largest $\chi$ values were found to be associated with $v_{s}<80 \mathrm{~mm} \mathrm{yr}^{-1}$ whereas none of the $v_{s}>80 \mathrm{~mm} \mathrm{yr}^{-1}$ subduction zones had $\chi$ values $>0.2$. Such behavior of the subduction interface seismogenic zone at the fastest subduction velocities is inconsistent with the theory that $M_{\max }$ is constant over subduction zones in the long term [e.g., McCaffrey, 2008]. Indeed, as the fastest subduction zones are associated with the shortest recurrence times [e.g., Gutscher and Westbrook, 2009], they are theoretically more prone to have experienced $M_{w} \geq 8.5$ earthquakes and to express large $\chi$ values during a limited time span. The variabilities in the potential size of earthquakes and in the long-term seismic coupling are thus likely to be real features. 
[69] In summary, our results demonstrate that the subduction velocity cannot be the only parameter that controls the subduction interface variability. The statistical portrait depicted in Figure 14 was not verified for all subduction interface parameters, especially for the genesis of $M_{w} \geq 8.5$ events. The correlation between the subduction interface geometry parameters $v_{s}, \varphi, \tau$ and $M_{\max }$ was generally low, and in most of the bivariate relations, the segments where $M_{w} \geq 8.5$ events occurred were generally out of the main trend (Figures 9, 10, and 12). Among other differences and in opposition to the results of Ruff and Kanamori [1980], the parameters $M_{\max }, M_{M R R}$ and $\chi$ appeared uncorrelated with $\varphi$. The relationship between seismic momentrelated parameters and the nature of the upper plate (Figure 11) likely represents an important ingredient to completing the picture. Subduction zones associated with continental upper plates were on average slower (the mean $v_{s}$ was $53 \pm 28 \mathrm{~mm} \mathrm{yr}^{-1}$ ) than intraoceanic subduction zones (the mean $v_{s}$ was $76 \pm 55 \mathrm{~mm} \mathrm{yr}^{-1}$ ). As a result, this can represent a possible consequence of the $\left[M_{\max } ; v_{s}\right]$ relation for $v_{s}<80 \mathrm{~mm} \mathrm{yr}^{-1}$ subduction zones. However, the underrepresentation of intraoceanic subduction zones can bias this observation.

\subsection{Conditions for $M_{w} \geq 8.5$ Earthquake Genesis}

[70] The seismic moment released during earthquake failures increases with the event rupture area [e.g., Hanks and Kanamori, 1979]. The potential earthquake magnitude of a given trench segment is thus conditioned by both the maximum possible rupture width and the maximum along-trench length along which the rupture is able to propagate.

[71] The maximum rupture width, which corresponds to the downdip extent $W$ of the subduction plate interface seismogenic zone, was found to be uncorrelated with $M_{\max }$ (Figure 12). Megaevents $\left(M_{w} \geq 8.5\right)$ were associated with the entire range of possible $W$ values, from the largest (e.g., $250 \mathrm{~km}$ in the Andaman; Table 1) to the smallest (e.g., $75 \mathrm{~km}$ in the central Aleutians; Table 1). The same trend was observed for the plate interface dip (possible values ranged from $9^{\circ}$ in the Andaman to $35^{\circ}$ in the central Aleutians; Table 1). The fact that megaevents were not associated with any particular value of $W$ highlights the dominant role played by the along-trench rupture propagation [Ruff, 1989; McCaffrey, 2007, 2008; Hayes and Conrad, 2007]. This means that subduction zones characterized by a limited lateral extent $(<500 \mathrm{~km}$; e.g., Yap, Palau,
Puysegur and Cotobato) [see Lallemand et al., 2005; Heuret, 2005] are unable to generate megaevents, while longer subduction zones may potentially be able to extend the rupture along their whole length (e.g., approximately $6000 \mathrm{~km}$ of potential lateral rupture in Sunda, South America or NE Japan-Kuril). The observed lateral ruptures of megaevents were, however, restricted to only limited portions of the trench system (500-2000 km) [e.g., McCann et al., 1979; Kostoglodov, 1988].

[72] To speculate on the reason for the natural cutoff that occurs in the lateral rupture of interplate subduction faults, it is necessary to recall the mechanism that produces interface events. The subducting plate complexity (i.e., variable sediment thickness, horsts and grabens, fracture zones, aseismic ridges and seamounts) and upper plate strength (see Bilek [2007] for a comprehensive review) are known to produce local frictional variations along the fault, focusing the high-slip location during an earthquake [e.g., Rice, 1993]. This concept is described by the asperity model, where asperity is seismically defined as the area dominated by stick-slip behavior and the high-slip location during an earthquake [e.g., Lay et al., 1982; Kanamori, 1986]. In this view, interface earthquake ruptures are segmented, being separated by weak zones (i.e., barriers [e.g., Seno, 2003]) that inhibit rupture propagation. We found that more than $75 \%$ of global subduction zones have $M_{\max } \geq$ 7.5 (Figure 8b), regardless of the subduction conditions, which implies that the inherited segmentation is always able to generate moderately large-sized earthquakes. Conversely, the occurrence of megaearthquakes was limited to only a few subduction zones (Figures 1 and 8b), requiring the progressive failure of adjacent asperities (i.e., multisegment ruptures [e.g., Thatcher, 1990; Ruff, 1996]). For example, at the Ecuador-Columbia margin, the area ruptured in 1906 as a single and wide segment $\left(M_{w}=\right.$ 8.6 event). This segment was composed of three adjacent seismic segments that ruptured independently into smaller-size events in $1942\left(M_{w}=7.8\right)$, $1958\left(M_{w}=7.7\right)$ and $1979\left(M_{w}=8.2\right)$ [Marcaillou et al., 2008; Bilek, 2009]. The genesis of megaevents should thus be promoted if the rupture is able to easily propagate laterally into adjacent segment(s) through possible barriers or weak zones (e.g., subducting ridges or fracture zones).

[73] The statistical results presented here show that such behavior seems to be preferentially enhanced in specific areas that are characterized by a neutral back-arc regime or continental upper 
plate (Figures 12a-12d), as well as those that are in the vicinity of slab borders (Figure 13).

\subsubsection{Upper Plate Strain, Plate Coupling, and Megaearthquake Genesis}

[74] Although compressive UPS values were underrepresented in current subduction zones (only 15\%, whereas neutral UPS values represent approximately $60 \%$ of the subduction segments analyzed here), it is noteworthy that $85 \%$ of the recorded $M_{\max } \geq 8.5$ events occurred at neutral UPS subductions. This observation yields to speculation concerning alternative mechanism from those usually though. Since the report by Uyeda and Kanamori [1979], megaearthquakes have indeed been generally associated with compressive backarc deformations. In this view, where the back-arc area is used as a strain tensor to determine the efficiency of the plate coupling [Lallemand et al., 2008], large compressive stresses recorded in the back-arc area are thought to reflect larger and stronger stress accumulations of the subduction fault and, in turn, larger asperities [Ruff and Kanamori, 1980]. However, as first highlighted by Hayes and Conrad [2007], this mechanism does not take into account that, even if this tectonic framework favors the release of a large seismic moment during the occurrence of the initial asperity rupture, the large critical stresses associated with adjacent asperities may inhibit the rupture from propagating laterally and, in turn, restrain the possibility for the generation of megaevents. The opposite scenario occurs with extensional UPS, where asperities are expected to be smaller. Low critical stresses should theoretically facilitate the lateral propagation of the rupture to adjacent asperities. However, a limited initial seismic moment release may not be sufficient to trigger megaevents. The statistical association of megaearthquakes with neutral subduction zones can thus be explained as being related to the most favorable interplay between a significantly large initial released seismic moment and a low critical stress for the lateral rupture propagation [Hayes and Conrad, 2007; Rosenau and Oncken, 2010; Corbi et al., submitted manuscript, 2010].

[75] This mechanism could also explain why any association between megaevents and single subduction parameters is missing. The UPS and plate coupling magnitude reflect the balance between driving and resistive forces (e.g., slab pull, bending and mantle resistance) [Lallemand et al., 2008] acting at a given subduction. This balance is sup- posed to be influenced by a wide range of subduction parameters and should be kinematically mirrored by combinations of the subduction velocity and absolute plate motion [e.g., Uyeda and Kanamori, 1979; Ruff and Kanamori, 1980; Conrad et al., 2004]. Lallemand et al. [2008] found that neutral subductions verify a $\left[V_{s u b} ; V_{u p}\right]$ relation that is satisfied by a wide range of kinematic combinations and subduction parameters. Thus, the condition that likely enhances the occurrence of megaearthquakes is not associated with any single tested subduction parameter. This is true even for those parameters that are commonly assumed to exert a primary control on the plate interface mechanical behavior. Moreover, neutral UPS may be indifferently associated with the advancing or retreating upper plates. This is in contrast with the arguments of several previous studies by researchers [Uyeda and Kanamori, 1979; Peterson and Seno, 1984; Conrad et al., 2004] who recognized that the occurrence of megaearthquakes correlates with the advancement of the upper plate.

[76] By assuming UPS as an indicator of the ability of the rupture to propagate laterally (that is, extensional, compressive and neutral UPS determine the increasing rupture potential length), it is possible to estimate the potential rupture area of a given segment in a $[U P S ; W]$ diagram (Figure 15). The smallest rupture areas should settled in the lower left corner of this diagram (short downdip and lateral rupture potential) and the largest ones would be in the upper right corner (large downdip and lateral rupture potential). The expected trend is verified in Figure 15; the extensional UPS and narrow seismogenic zones are associated with low $M_{\max }$, whereas the neutral UPS and large seismogenic zones are usually associated with the largest events. However, the largest magnitudes observed in several subduction zones were found to be smaller than what is suggested by their $W$ and UPS values. Owing to the century over which these instrumental observations were made, we hypothesize that these subduction zones have not yet experienced the largest earthquake magnitude that they should be able to produce. The $M_{\max }$ observed for subduction zones with similar $W$-UPS pairs could yield an estimate of their actual magnitude potential. For example, the Sandwich and southern Kermadec (recorded $M_{\max }<7.5$ ) could produce at $\operatorname{most} M_{w}=$ 8.1 events. The Cocos Ridge subduction (recorded $M_{\max }<7.5$ ) could produce $M_{w} \geq 8.0$ events, and megaevents are likely to occur in the Antilles, Costa Rica and Manila segments $(7.5 \leq$ recorded $\left.M_{\max }<8.0\right)$. A magnitude potential $M_{w}=9.0$ could 


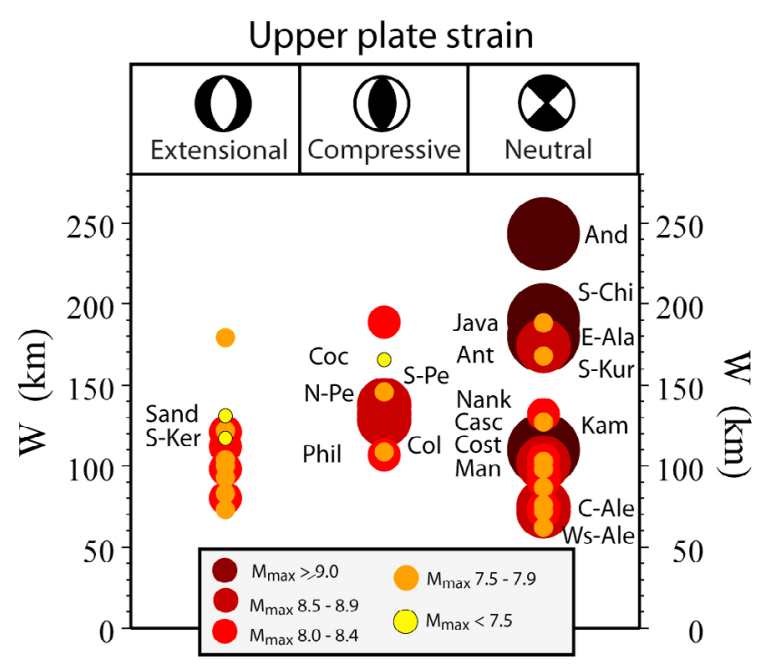

Figure 15. Potential rupture area of the subduction plate interfaces in an [upper plate strain; $W$ ] field. In this diagram, the extensional, compressive, and neutral upper plate strains determine the increasing values of $L_{\max }$. The potential area of rupture increases from the bottom left corner toward the top right corner. Trench segment symbols are defined as in Table 1. Labeled subduction zones located on the left side of the extensional, neutral, or compressive segments refer to yellow and orange dots ( $M_{\max }<8.0$ segments), except for Nankai. Those that are located on the right side refer to brown and black dots $\left(M_{\max }<8.5\right.$ segments). The dot size increases as a function of $M_{\max }$.

characterize Cascadia. A similar event did occur in the year 1700 , and this region is currently on high alert for future earthquakes and tsunamis that are larger than those known from written and instrumental records $\left(7.5 \leq M_{\max }<8.0\right.$ [Satake et al., 2003]).

\subsubsection{Three-Dimensional Control of Megaearthquake Genesis}

[77] Finally, it is appealing to speculate that a spatial preferential setting controls the occurrence of megaearthquakes $\left(M_{w} \geq 8.5\right)$. Theoretically, a differential trench migration is expected along the strike length; trench motion rates are inversely related with the slab width and decrease near the center of the slabs [e.g., Morra et al., 2006; Schellart et al., 2007; Guillaume et al., 2010]. As a first-order consequence, the local upper plate compressive strain is expected to progressively diminish toward the slab edges. This prediction is reasonably respected in natural cases where backarc compressions are preferentially located at slab centers (e.g., Japan and South America) and exten- sion is often reached at slab edges [Heuret and Lallemand, 2005; Heuret, 2005; Schellart, 2008]. In our view, such a scenario should tune the plate coupling and normal stress acting on the subduction fault, enhancing the occurrence of megaevents at slab edges. A similar background relationship may thus explain the observed frequency of large earthquakes near the borders of long trenches, such as in South America, Aleutian-Alaska, Sunda and NE Japan-Kuriles (Figure 13). Largest $\tau$ were instead observed toward slab centers, in agreement with Scholz and Small [1997] observation of an inverse relationship between small earthquake seismicity and large earthquakes [Scholz and Small, 1997]. However, this inverse relation is only verified for segments where megaevents have occurred. The general law is rather a negligible but positive correlation between $\tau$ and $M_{\max }(\mathrm{R}=0.25$; Figure 3$)$. In any case $\tau$ is of questionable use in predicting extreme events because megaevents are not part of the Gutenberg and Richter [1954] distribution of the small earthquakes [Scholz, 2002].

[78] The three-dimensional control of megaevents genesis can be described for an idealized single wide $(\mathrm{L}>5000 \mathrm{~km})$ trench system where large normal compressive stresses associated with the compressive UPS of the slab center diminish toward the lateral slab edges, reaching neutral strain at one border and extensional strain at the other border. At the neutral edge, the moderate compressive stresses enable the nucleation and lateral propagation of large ruptures over a large number of asperities. The genesis of megaevents is possible. Such events release almost the entire available seismic moment. As a consequence, the plate interface has a large seismic coupling $\left(v_{s} \approx v_{s s}\right)$, low seismic moment remains for additional events and seismicity is characterized by a relatively small number of large-sized events (e.g., southern Chile and eastern Alaska). Toward the slab center, normal compressive stresses at the plate interface increase, and relatively large ruptures are less able to propagate toward adjacent asperities. A large earthquake magnitude potential remains ( $\left.M_{\max } 8.0-8.5\right)$ but the proportion of uncoupled areas increases. The seismicity is characterized by a relatively large number of moderately sized events and intermediate seismic coupling (e.g., Japan). Toward the extensional edge, normal compressive stresses become small. Asperities become increasingly smaller and more isolated. The proportion of uncoupled areas is at a maximum, but the large subduction velocities associated with back-arc spreading enables the few asperities to fail frequently. Large moment rates can occur, but the magnitude 
potential $\left(M_{\max } \leq 8.1\right)$ and seismic coupling $(\chi \leq 0.2)$ values are low. The two latter features best characterize the seismicity of such regions (e.g., northern Tonga, New Hebrides and the Marianas).

\section{Conclusions}

[79] Statistics performed over worldwide subduction seismogenic zones reveal some of the major features of the seismogenesis of subduction plate interfaces. We confirmed that most seismogenic zones end in the fore-arc mantle rather than at the upper plate Moho depth. The subduction velocity was found to likely be the first-order controlling parameter of the variability in physical characteristics of the plate interfaces, determining both the geometry and the mechanical behavior. As such, fast subduction zones and cold slabs were found to be associated with large and steep plate interfaces, which, in turn, had large seismic rates. The earthquake magnitude potential and occurrence of $M_{w} \geq$ 8.5 events, in particular, determined both the level of the seismic moment that was released and whether the subduction was seismically coupled, regardless of the seismic rate. The subduction velocity was not able to account for the entire earthquake magnitude potential diversity observed along trenches. In fact, $M_{w} \geq 8.5$ events preferentially occurred in the vicinity of slab edges, where the upper plate was continental and the back-arc strain was neutral. This observation was interpreted in terms of the level of compressive normal stresses along the plate interface. Large lateral ruptures associated with $M_{w} \geq 8.5$ events should be promoted in neutral subduction zones due to moderate compressive stresses along the plate interface, which enable a rupture to easily propagate laterally.

\section{Notation}

$L$ along-strike length of seismic activity distribution $(\mathrm{km})$.

$W$ downdip width of seismic activity distribution $(\mathrm{km})$.

$N$ number of plate interface thrusts events.

$T$ analyzed time period (yr).

$M_{\text {max }}$ highest earthquake magnitude observed along the section.

$M R R$ moment released rate $(\mathrm{N}$ m per century and per $10^{3} \mathrm{~km}$ of trench length).

$M_{o}^{i} \quad$ seismic moment released by an individual earthquake $(\mathrm{N} \mathrm{m})$.

$M_{M R R}$ equivalent representative magnitude in the sense of Ruff and Kanamori [1980]. $\chi \quad$ seismic coupling coefficient.

$\chi_{(n)}$ trench normal component of the seismic coupling coefficient.

$\tau$ seismic rate (number of events per century and per $10^{3} \mathrm{~km}$ of trench).

$v_{s}$ subduction velocity $\left(\mathrm{mm} \mathrm{yr}^{-1}\right)$.

$o_{s}$ subduction velocity obliquity relative to the trench-normal direction (deg).

$v_{s(n)}$ trench normal component of the subduction velocity $\left(\mathrm{mm} \mathrm{yr}^{-1}\right)$.

$v_{c}$ main plates convergence velocity $(\mathrm{mm}$ $\left.\mathrm{yr}^{-1}\right)$.

$o_{c}$ convergence velocity obliquity relatively to the trench-normal direction (deg).

$v_{c(n)}$ trench normal component of the convergence velocity $\left(\mathrm{mm} \mathrm{yr}^{-1}\right)$.

$V_{u p} \quad$ absolute upper plate velocity ( $\mathrm{mm} / \mathrm{yr}$; HS3 reference frame).

$V_{u p(n)}$ trench normal component of the upper plate velocity $\left(\mathrm{mm} \mathrm{yr}^{-1}\right)$.

$V_{t}$ absolute trench velocity ( $\mathrm{mm} / \mathrm{yr}$; HS3 reference frame).

$V_{t(n)}$ trench normal component of the trench velocity $\left(\mathrm{mm} \mathrm{yr}^{-1}\right)$.

$V_{\text {sub }}$ absolute subducting plate velocity ( $\mathrm{mm} / \mathrm{yr}$; HS3 reference frame).

$V_{\text {sub(n) }}$ trench normal component of the subducting plate velocity $\left(\mathrm{mm} \mathrm{yr}^{-1}\right)$.

$v_{s s} \quad$ seismic slip rate $\left(\mathrm{mm} \mathrm{yr}^{-1}\right)$.

$\mu$ plate interface rigidity.

UPS upper plate strain class (in the sense of Lallemand et al. [2008]).

$U$ updip limit of the seismogenic zone $(\mathrm{km})$.

$D$ downdip limit of the seismogenic zone $(\mathrm{km})$.

$U_{z}$ depth of updip limit $U(\mathrm{~km})$.

$D_{z}$ depth of downdip limit $D(\mathrm{~km})$.

$U_{x}$ horizontal distance of $U$ from trench $(\mathrm{km})$.

$D_{x}$ horizontal distance of $D$ from trench $(\mathrm{km})$.

$\theta$ dip angle of the seismogenic zone (deg).

$W_{x}$ horizontal extent of the seismogenic zone width $(\mathrm{km})$.

$W_{z} \quad$ vertical extent of the seismogenic zone width $(\mathrm{km})$.

$D_{\text {arc- } t}$ mean arc-trench distance $(\mathrm{km})$.

$\varphi$ thermal parameter of the subducting plate measured at trench $(\mathrm{km})$.

$A$ age of the subducting plate measured at trench (Myr).

$z_{\text {Moho }}$ fore-arc Moho depth $(\mathrm{km})$. 
$\Delta z$ depth difference between the fore-arc Moho and the downdip limit of the seismogenic zone $(\mathrm{km})$.

\section{Acknowledgments}

[80] We thank Kelin Wang, an anonymous reviewer, and the editor for constructive suggestions which improved the quality of the manuscript. This research was supported as part of the Eurohorcs/ESF-European Young Investigators Awards Scheme (F.F.), by funds from the National Research Council of Italy and other National Funding Agencies participating in the 3rd Memorandum of Understanding, as well as from the EC Sixth Framework Programme. Discussion with Clint Conrad has been fundamental to strengthen ideas related to the importance of neutral regime in enhancing the triggering of $M_{w} \geq 8.5$ earthquakes.

\section{References}

Baumberger, T., F. Heslot, and B. Perrin (1994), Crossover from creep to inertial motion in friction dynamics, Nature, 367, 544-546, doi:10.1038/367544a0.

Bilek, S. (2007), Influence of subducting topography on earthquake rupture, in The Seismogenic Zone of Subduction Thrust Faults, edited by T. H. Dixon and J. Casey Moore, pp. 123-146, Columbia Univ. Press, New York.

Bilek, S. (2009), Seismicity along the South America subduction zone: Review of large earthquakes, tsunami and subduction zone complexity, Tectonophysics, doi:10.1016/j. tecto.2009.02.037, in press.

Bird, P., and Y. Y. Kagan (2004), Plate-tectonic analysis of shallow seismicity: Apparent boundary width, beta, corner magnitude, coupled lithosphere and coupling in seven tectonic settings, Bull. Seismol. Soc. Am., 94(6), 2380-2399, doi:10.1785/0120030107.

Bird, P., Y. Y. Kagan, D. D. Jackson, F. P. Schoenberg, and M. J. Werner (2009), Linear and nonlinear relations between relative plate velocity and seismicity, Bull. Seismol. Soc. Am., 99, 3097-3113, doi:10.1785/0120090082.

Brune, J. N. (1968), Seismic moment, seismicity, and rate of slip along major fault zones, J. Geophys. Res., 73, 777784, doi:10.1029/JB073i002p00777.

Byrne, D. E., D. M. Davis, and L. R. Sykes (1988), Loci and maximum size of thrust earthquakes and the mechanics of the shallow region of subduction zones, Tectonics, 7, 833857, doi:10.1029/TC007i004p00833.

Byrne, D. E., L. R. Sykes, and D. M. Davies (1992), Great thrust earthquakes and aseismic slip along the plate boundary of the Makran subduction zone, J. Geophys. Res., 97(B1), 449-478, doi:10.1029/91JB02165.

Clague, J. J. (1997), Evidence for large earthquakes at the Cascadia subduction zone, Rev. Geophys., 35, 439-460.

Conrad, C. P., S. Bilek, and C. Lithgow-Bertelloni (2004), Great earthquakes and slab pull: Interaction between seismic coupling and plate-slab coupling, Earth Planet. Sci. Lett., 218, 109-122, doi:10.1016/S0012-821X(03)00643-5.

Currie, C. A., R. D. Hyndman, K. Wang, and V. Kostoglodov (2002), Thermal models of the Mexico subduction zone: Implications for the megathrust seismogenic zone, J. Geophys. Res., 107(B12), 2370, doi:10.1029/2001JB000886.
DeMets, C., R. Gordon, D. Argus, and S. Stein (1990), Current plate motion, Geophys. J. Int., 101, 425-478, doi:10.1111/ j.1365-246X.1990.tb06579.x.

Dessa, J.-X., F. Klingelhoefer, D. Graindorge, C. André, H. Permana, M.-A. Gutscher, A. Chauhan, S. C. Singh, and the SUMATRA-OBS Scientific Team (2009), Megathrust earthquakes can nucleate in the forearc mantle: Evidence from the 2004 Sumatra event, Geology, 37(7), 659-662, doi:10.1130/G25653A.1.

Dixon, T. H. (1993), GPS measurement of relative motion of the Cocos and Caribbean plates and strain accumulation across the Middle America trench, Geophys. Res. Lett., 20, 2167-2170, doi:10.1029/93GL02415.

Dziewonski, A. M., and J. H. Woodhouse (1981), Determination of earthquake source parameters from waveform data for studies of global and regional seismicity, J. Geophys. Res., 86, 2825-2852, doi:10.1029/JB086iB04p02825.

Engdahl, R., and A. Villaseñor (2002), Global seismicity: 1900-1999, in International Handbook of Earthquake and Engineering Seismology, Part A, edited by W. H. K. Lee et al., chap. 41, pp. 665-690, Academic, Amsterdam.

Engdahl, R., R. Van Der Hilst, and R. Buland (1998), Global teleseismic earthquake relocation with improved travel times and procedures for depth determination, Bull. Seismol. Soc. Am., 88, 722-743.

Fedotov, S. A., A. V. Solomatin, and S. D. Chernyshev (2007), Long-term earthquake prediction for the KurilKamchatka arc for 2006-2011 and successful prediction for the Middle Kuril Island earthquake, 15.11.2006, Ms = 8.2, J. Volcanol. Seismol., 1(3), 143-163, doi:10.1134/ S0742046307030013.

Gripp, A. E., and R. G. Gordon (2002), Young tracks of hot spots and current plate velocities, Geophys. J. Int., 150, 321-361, doi:10.1046/j.1365-246X.2002.01627.x.

Guillaume, B., F. Funiciello, C. Faccenna, J. Martinod, and V. Olivetti (2010), Spreading pulses of the Tyrrhenian Sea during the narrowing of the Calabrian subduction zone, Geology, 38(9), 819-822, doi:10.1130/G31038.1.

Gutenberg, B., and C. F. Richter (1954), Seismicity of the Earth and Associated Phenomena, 310 pp., Princeton Univ. Press, Princeton, N. J.

Gutscher, M.-A., and G. K. Westbrook (2009), Great earthquakes in slow subduction, low taper margins, in Subduction Zone Dynamics, edited by S. Lallemand and F. Funiciello, pp. 119-134, doi:10.1007/978-3-540-87974-9, Springer, Berlin.

Hanks, T. C., and H. Kanamori (1979), Moment magnitude scale, J. Geophys. Res., 84(B5), 2348-2350, doi:10.1029/ JB084iB05p02348.

Hayes, C. W., and C. P. Conrad (2007), Subduction dynamics and great earthquakes, Eos Trans. $A G U, 88(52)$, Fall Meet. Suppl., Abstract T52A-05.

Heuret, A. (2005), Dynamique des zones de subduction: Etude statistique globale et approche analogique-Subduction zones dynamics: Global statistical study and experimental modelling, Ph.D. thesis, Univ. Montpellier II, Montpellier, France. (Available at http://tel.archives-ouvertes.fr/tel00108728/en/.

Heuret, A., and S. Lallemand (2005), Plate motions, slab dynamics and back-arc deformation, Phys. Earth Planet. Inter., 149, 31-51, doi:10.1016/j.pepi.2004.08.022.

Hyndman, R. D., and S. Peacock (2003), Serpentinization of the forearc mantle, Earth Planet. Sci. Lett., 212, 417-432.

Hyndman, R. D., and K. Wang (1993), Thermal constraints on the zone for major thrust earthquake failure: The Cascadia 
subduction zone, J. Geophys. Res., 98, 2039-2060, doi:10.1029/92JB02279.

Hyndman, R. D., M. Yamano, and K. Wang (1995), Thermal constraints on the seismogenic portion of the southwestern Japan subduction thrust, J. Geophys. Res., 100, 15,37315,392, doi:10.1029/95JB00153.

Hyndman, R. D., M. Yamano, and D. A. Oleskevich (1997), The seismogenic zone of subduction thrust fault, Isl. Arc, 6, 244-260, doi:10.1111/j.1440-1738.1997.tb00175.x.

Ishii, M., P. M. Shearer, H. Houston, and J. E. Vidale (2005), Extent, duration and speed of the 2004 Sumatra-Andaman earthquake inaged by Hi-Net array, Nature, 435, 933-936, doi:10.1038/nature03675.

Jarrard, R. D. (1986), Relations among subduction parameters, Rev. Geophys., 24, 217-284, doi:10.1029/RG024i002p00217.

Johnson, J. M., Y. Tanioka, L. J. Ruff, K. Satake, H. Kanamori, and L. R. Sykes (1994), The great Aleutian earthquake, Pure Appl. Geophys., 142, 3-28, doi:10.1007/BF00875966.

Kanamori, H. (1977), The energy release in great earthquakes, J. Geophys. Res., 82, 2981-2987, doi:10.1029/ JB082i020p02981.

Kanamori, H. (1986), Rupture process of subduction-zone earthquakes, Annu. Rev. Earth Planet. Sci., 14, 293-322, doi:10.1146/annurev.ea.14.050186.001453.

Kelleher, J., J. Savino, H. Rowlett, and W. McCann (1974), Why and where great thrust earthquakes occur along island arcs, J. Geophys. Res., 79, 4889-4899, doi:10.1029/ JB079i032p04889.

Kirby, S. H., S. Stein, E. A. Okal, and D. C. Rubie (1996), Metastable mantle phase transformations and deep earthquakes in subducting oceanic lithosphere, Rev. Geophys., 34(2), 261-306, doi:10.1029/96RG01050.

Kostoglodov, V. (1988), Sediment subduction: A probable key for seismicity and tectonics at active plate boundaries, Geophys. J., 94, 65-72.

Lallemand, S., A. Heuret, and D. Boutelier (2005), On the relationships between slab dip, back-arc stress, upper plate absolute motion and crustal nature in subduction zones, Geochem. Geophys. Geosyst., 6, Q09006, doi:10.1029/ 2005GC000917.

Lallemand, S., A. Heuret, C. Faccenna, and F. Funiciello (2008), Subduction dynamics as revealed by trench migration, Tectonics, 27, TC3014, doi:10.1029/2007TC002212.

Lay, T., H. Kanamori, and L. Ruff (1982), The asperity model and the nature of large subduction zone earthquakes, Earthquake Predict. Res., 1, 3-71.

Lay, T., et al. (2005), The great Sumatra-Andaman earthquake of 26 December 2004, Science, 308(5725), 1127-1133, doi:10.1126/science.1112250.

Lundgren, P., M. Protti, A. Donnellan, M. Heflin, E. Hernandez, and D. Jefferson (1999), Seismic cycle and plate margin deformation in Costa Rica: GPS observations from 1994 to 1997, J. Geophys. Res., 104(B12), 28,915-28,926, doi:10.1029/1999JB900283.

Madariaga, R., M. Metois, C. Vigny, and J. Campos (2010), Central Chile finally breaks, Science, 328(5975), 181-182, doi:10.1126/science.1189197.

Marcaillou, B., G. Spence, K. Wang, J.-Y. Collot, and A. Ribodetti (2008), Thermal segmentation along the N. Ecuador-S. Colombia margin $\left(1-4^{\circ} \mathrm{N}\right)$ : Prominent influence of sedimentation rate in the trench, Earth Planet. Sci. Lett., 272(1-2), 296-308, doi:10.1016/j.epsl.2008.04.049.

McCaffrey, R. (1994), Dependence of earthquake size distributions on convergence rate at subduction zones, Geophys. Res. Lett., 21(21), 2327-2330, doi:10.1029/94GL02153.
McCaffrey, R. (1997a), Statistical significance of the seismic coupling coefficient, Bull. Seismol. Soc. Am., 87, 1069-1073.

McCaffrey, R. (1997b), Influences of recurrence times and fault zone temperature on the age-rate dependence of subduction zone seismicity, J. Geophys. Res., 102, 22,83922,854, doi:10.1029/97JB01827.

McCaffrey, R. (2007), The next great earthquake, Science, 315, 1675-1676, doi:10.1126/science.1140173.

McCaffrey, R. (2008), Global frequency of magnitude 9 earthquakes, Geology, 36(3), 263-266, doi:10.1130/G24402A.1.

McCann, W. R., S. P. Nishenko, L. R. Sykes, and J. Krause (1979), Seismic gaps and plate tectonics: Seismic potential for major boundaries, Pure Appl. Geophys., 117, 10821147, doi:10.1007/BF00876211.

Molnar, P. (1979), Earthquake recurrence intervals and plate tectonics, Bull. Seismol. Soc. Am., 69(1), 115-133.

Moore, C., and D. Saffer (2001), Updip limit of the seismogenic zone beneath the accretionary prism of southwest Japan: An effect of diagenetic to low-grade metamorphic processes and increasing effective stress, Geology, 29, 183-186, doi:10.1130/0091-7613(2001)029<0183:ULOTSZ $>2.0$. $\mathrm{CO} ; 2$.

Moore, D. E., D. A. Lockner, M. Shengli, R. Summers, and J. D. Byerlee (1997), Strength of serpentinites gouges at elevated temperatures, J. Geophys. Res., 102, 14,78714,801, doi:10.1029/97JB00995.

Morra, G., K. Regenauer-Lieb, and D. Giardini (2006), Curvature of oceanic arcs, Geology, 34(10), 877-890, doi:10.1130/ G22462.1.

Müller, R., W. Roest, J.-Y. Royer, L. Gahagan, and J. Sclater (1997), Digital isochrons of the world's ocean floor, J. Geophys. Res., 102, 3211-3214, doi:10.1029/96JB01781.

Norabuena, E. O., L. Leffler, A. Mao, T. H. Dixon, S. Stein, I. S. Sacks, L. Ocola, and M. Ellis (1998), Space geodetic observations of Nazca-South America convergence across the central Andes, Science, 279, 358-362, doi:10.1126/ science.279.5349.358.

Norabuena, E. O., et al. (2004), Geodetic and seismic constraints on some seismogenic zone processes in Costa Rica, J. Geophys. Res., 109, B11403, doi:10.1029/2003JB002931.

Oleskevich, D. A., R. D. Hyndman, and K. Wang (1999), The updip and downdip limits to great subduction earthquakes: Thermal and structural models of Cascadia, south Alaska, SW Japan, and Chile, J. Geophys. Res., 104(B7), 14,96514,991, doi:10.1029/1999JB900060.

Pacheco, J., and L. Sykes (1992), Seismic moment catalog for large shallow earthquakes from 1900 to 1989, Bull. Seismol. Soc. Am., 82, 1306-1349.

Pacheco, J. F., L. R. Sykes, and C. H. Scholz (1993), Nature of seismic coupling along simple plate boundaries of the subduction type, J. Geophys. Res., 98, 14,133-14,159, doi:10.1029/93JB00349.

Peacock, S., and R. D. Hyndman (1999), Hydrous minerals in the mantle wedge and the maximum depth of subduction thrust earthquakes, Geophys. Res. Lett., 26, 2517-2520.

Peterson, E. T., and T. Seno (1984), Factors affecting seismic moment release rates in subduction zones, J. Geophys. Res., 89, 10,233-10,248, doi:10.1029/JB089iB12p10233.

Reinen, T., E. Tullis, and J. D. Weeks (1992), Two-mechanism model for frictional sliding of serpentinite, Geophys. Res. Lett., 19, 1535-1538, doi:10.1029/92GL01388.

Rice, J. R. (1993), Spatiotemporal complexity of slip on a fault, J. Geophys. Res., 98(B6), 9885-9907, doi:10.1029/ 93JB00191. 
Rosenau, M., and O. Oncken (2010), Shocks in a box 3D: Experimental insights into seismotectonic segmentation and synchronization of megathrust earthquakes in subduction zones, paper presented at GeoMod 2010, Fac. of Sci., Univ. of Lisbon, Lisbon.

Ruff, L. J. (1989), Do trench sediments affect great earthquake occurrence in subduction zones?, in Subduction Zones Part I, edited by L. J. Ruff and H. Kanamori, Pure Appl. Geophys., 129, 263-282.

Ruff, L. J. (1996), Large earthquakes in subduction zones: Segment interaction and recurrence times, in Subduction: Top to Bottom, Geophys. Monogr. Ser., vol. 96, edited by G. E. Bebout et al., pp. 91-104, AGU, Washington, D. C.

Ruff, L. J., and H. Kanamori (1980), Seismicity and the subduction process, Phys. Earth Planet. Inter., 23, 240-252, doi:10.1016/0031-9201(80)90117-X.

Ruff, L. J., and B. W. Tichelaar (1996), What control the seismogenic plate interface in subduction zones?, in Subduction: Top to Bottom, Geophys. Monogr. Ser., vol. 96, edited by G. E. Bebout et al., pp. 105-111, AGU, Washington, D. C.

Ruppert, N. A., J. M. Lees, N. P. Kozyreva (2007), Seismicity, earthquakes and structure along the Alaska-Aleutian and Kamchatka-Kutile subduction zones: A review, in Volcanism and Subduction: The Kamchatka Region, Geophys. Monogr. Ser., vol. 172, edited by J. Eichelberger et al., pp. 129-144, doi:10.1029/172GM12, AGU, Washington, D. C.

Satake, K. (1993), Depth distribution of coseismic slip along the Nankai Through, Japan, from joint inversion of geodetic and tsunami data, J. Geophys. Res., 98, 4553-4565, doi:10.1029/92JB01553.

Satake, K., and B. F. Atwater (2007), Long-term perspectives on giant earthquakes and tsunamis at subduction zones, Annu. Rev. Earth Planet. Sci. Lett., 35, 349-374.

Satake, K., K. Wang, and B. F. Atwater (2003), Fault slip and seismic moment of the 1700 Cascadia earthquake inferred from Japanese tsunami descriptions, J. Geophys. Res., 108(B11), 2535, doi:10.1029/2003JB002521.

Savage, J. C. (1983), A dislocation model of strain accumulation and release at a subduction zone, J. Geophys. Res., 88, 4984-4996, doi:10.1029/JB088iB06p04984.

Schellart, W. P. (2008), Overriding plate shortening and extension above subduction zones: A parametric study to explain formation of the Andes Mountains, Geol. Soc. Am. Bull., 120(11), 1441-1454, doi:10.1130/B26360.1.

Schellart, W. P., D. J. Freeman, A. Stegman, L. Moresi, and D. May (2007), Evolution and diversity of subduction zones controlled by slab width, Nature, 446, 308-311, doi:10.1038/ nature 05615 .

Scholz, C. H. (2002), The Mechanics of Earthquakes and Faulting, 429 pp., Cambridge Univ. Press, Cambridge, U. K.

Scholz, C. H., and J. Campos (1995), On the mechanism of seismic decoupling and back-arc spreading at subduction zones, J. Geophys. Res., 100, 22,103-22,115, doi:10.1029/ 95JB01869.

Scholz, C. H., and C. Small (1997), The effect of seamounts subduction on seismic coupling, Geology, 25, 487-490, doi:10.1130/0091-7613(1997)025<0487:TEOSSO >2.3. $\mathrm{CO} ; 2$.
Schwartz, S. Y., and H. R. DeShon (2007), Distinct up-dip limits to geodetic locking and microseismicity at the northern Costa Rica seismogenic zone: Evidence for two mechanical transitions, in The Seismogenic Zone of Subduction Thrust Faults, edited by T. Dixon and J. C. Moore, pp. 576-599, Columbia Univ. Press, New York.

Schwartz, S. Y., T. Lay, and L. J. Ruff (1989), Source process of the great 1971 Solomon Islands doublet, Phys. Earth Planet. Inter., 56(3-4), 294-310, doi:10.1016/0031-9201 (89)90164-7.

Seno, T. (2003), Fractal asperities, invasion of barriers, and interface earthquakes, Earth Planets Space, 55(11), 649-665.

Seno, T. (2005), Variation of downdip limit of the seismogenic zone near the Japanese islands: Implications for the serpentinization mechanism of the fore-arc mantle wedge, Earth Planet. Sci. Lett., 231, 249-262, doi:10.1016/j.eps1. 2004.12.027.

Siebert, L., and T. Simkin (2002), Volcanoes of the world: An illustrated catalog of Holocene volcanoes and their eruptions, Global Volcanism Program Digital Inf. Ser., GVP-3, Smithsonian Inst., Washington, D. C. (Available at http://www. volcano.si.edu/world/)

Stein, S., and E. A. Okal (2007), Ultralong period seismic study of the December 2004 Indian Ocean earthquake and implications for regional tectonics and the subduction process, Bull. Seismol. Soc. Am., 97(1A), S279-S295, doi:10.1785/0120050617.

Thatcher, W. (1990), Order and diversity in the modes of circum-Pacific earthquakes recurrence, J. Geophys. Res., 95, 2609-2623, doi:10.1029/JB095iB03p02609.

Thatcher, W., and J. B. Rundle (1984), A viscoelastic coupling model for cyclic deformation due to periodically repeated earthquakes at subduction zones, J. Geophys. Res., 89, 7631-7640, doi:10.1029/JB089iB09p07631

Tichelaar, B. W., and L. J. Ruff (1993), Depth of seismic coupling along subduction zones, J. Geophys. Res., 98, $2017-$ 2037, doi:10.1029/92JB02045.

Uyeda, S., and H. Kanamori (1979), Back-arc opening and the mode of subduction, J. Geophys. Res., 84, 1049-1061, doi:10.1029/JB084iB03p01049.

Vrolijk, P. (1990), On the mechanical role of smectite in subduction zones, Geology, 18(8), 703-707, doi:10.1130/00917613(1990)018<0703:OTMROS $>2.3 . C O ; 2$.

Wada, I., and K. Wang (2009), Common depth of slab-mantle decoupling: Reconciling diversity and uniformity of subduction zones, Geochem. Geophys. Geosyst., 10, Q10009, doi:10.1029/2009GC002570.

Wang, K., T. Mulder, G. C. Rogers, and R. D. Hyndman (1995), Case for very low coupling stress on the Cascadia subduction fault, J. Geophys. Res., 100, 12,907-12,918, doi:10.1029/95JB00516.

Wu, B., C. P. Conrad, A. Heuret, C. Lithgow-Bertelloni, and S. Lallemand (2008), Reconciling strong slab pull and weak plate bending: The plate motion constraint on the strength of mantle slabs, Earth Planet. Sci. Lett., 272, 412-421, doi:10.1016/j.eps1.2008.05.009. 